\title{
Effects of Black Garlic Extract and Nanoemulsion on the Deoxy Corticosterone Acetate-Salt Induced Hypertension and Its Associated Mild Cognitive Impairment in Rats
}

\author{
Chun-Yu Chen ${ }^{1,+}$, Tsung-Yu Tsai ${ }^{1,+}$ and Bing-Huei Chen ${ }^{1,2, *(D)}$ \\ 1 Department of Food Science, Fu Jen Catholic University, New Taipei City 24205, Taiwan; \\ pack24578@yahoo.com.tw (C.-Y.C.); tytsai@mail.fju.edu.tw (T.-Y.T.) \\ 2 Department of Nutrition, China Medical University, Taichung 40401, Taiwan \\ * Correspondence: 002622@mail.fju.edu.tw; Tel.: +886-2-2905-3626 \\ + Equally contributed to this article.
}

Citation: Chen, C.-Y.; Tsai, T.-Y.; Chen, B.-H. Effects of Black Garlic Extract and Nanoemulsion on the Deoxy Corticosterone Acetate-Salt Induced Hypertension and Its Associated Mild Cognitive Impairment in Rats. Antioxidants 2021, 10, 1611. https://doi.org/ 10.3390/antiox10101611

Academic Editors:

Sara Jaramillo-Carmona, Rafael Guillén Bejarano and Sergio López

Received: 27 August 2021

Accepted: 7 October 2021

Published: 13 October 2021

Publisher's Note: MDPI stays neutral with regard to jurisdictional claims in published maps and institutional affiliations.

Copyright: (c) 2021 by the authors. Licensee MDPI, Basel, Switzerland. This article is an open access article distributed under the terms and conditions of the Creative Commons Attribution (CC BY) license (https:// creativecommons.org/licenses/by/ $4.0 /)$.

\begin{abstract}
Organosulfur compounds, phenolic acids and flavonoids in raw and black garlic were determined, and followed by preparation of black garlic nanoemulsion for studying their effects on deoxycorticosterone acetate-salt-induced hypertension and associated mild cognitive impairment in rats. Three organosulfur compounds, including diallyl sulfide $(87.8 \mu \mathrm{g} / \mathrm{g})$, diallyl disulfide $(203.9 \mu \mathrm{g} / \mathrm{g})$ and diallyl trisulfide $(282.6 \mu \mathrm{g} / \mathrm{g})$ were detected in black garlic by GC-MS, while gallic acid $(19.19 \mu \mathrm{g} / \mathrm{g})$, p-coumaric acid $(27.03 \mu \mathrm{g} / \mathrm{g})$ and quercetin $(22.77 \mu \mathrm{g} / \mathrm{g})$ were detected by UPLC-MS/MS. High doses of both black garlic extract and nanoemulsion prepared using Tween-80, glycerol, grapeseed oil and water could decrease systolic blood pressure through the elevation of bradykinin and nitric oxide levels as well as diminish aldosterone and angiotensin II levels in rats. In Morris water maze test, they could significantly decrease escape latency and swimming distance and increase the time spent in the target quadrant, accompanied by a decline of acetylcholinesterase activity and malondialdehyde level in the hippocampus as well as a rise in glutathione level and activities of superoxide dismutase, catalase and glutathione peroxidase. In addition, the levels of tumor necrosis factor, interleukin- 6 and interleukin- $1 \beta$ were reduced. Effects of lowering blood pressure and improving learning/memory ability in rats followed the order: lisinopril > black garlic nanoemulsion $>$ black garlic extract.
\end{abstract}

Keywords: black garlic nanoemulsion; organosulfur compounds; phenolic acids and flavonoids; Morris water maze test; systolic blood pressure; rats

\section{Introduction}

Garlic (Allium sativum) is a popular spice used in many kinds of foods during cooking. Many studies have demonstrated that the consumption of garlic can be effective against chronic diseases such as diabetes and cancer [1,2], which can be attributed to the presence of functional components such as allicin and S-methyl cysteine sulfoxide. However, due to the presence of its pungent odor, the application of garlic to the food industry has been limited. Thus, in recent years many processing techniques have been developed to remove this pungent odor. For instance, black garlic is a naturally aged product without a pungent odor.

Accordingly, black garlic can be produced from raw garlic under high-temperature and high-humidity conditions. During aging, raw garlic color can turn into black caused by the Maillard reaction and caramelization, accompanied by the conversion of pungent odor compounds to tasteless compounds [3]. In addition, compared to raw garlic, black garlic possessed a stronger antioxidant activity, as evidenced by enhancement of activities of superoxide dismutase (SOD) and catalase, as well as polyphenol level by 13- and 10- and 7-fold, respectively [4]. In addition to organosulfur compounds, the presence 
of polyphenols in black garlic should also play an important role in biological activity. More specifically, the levels of total phenolic acid and total flavonoid were reported to be $8.20 \mathrm{mg}$ gallic acid equivalent (GAE)/g and $1.92 \mu \mathrm{g}$ catechin $/ \mathrm{mg}$ in black garlic, respectively, while in raw garlic, the levels were $0.78 \mathrm{mg} \mathrm{GAE} / \mathrm{g}$ and $1.40 \mu \mathrm{g}$ catechin/mg $[5,6]$. This difference may be accounted for by release of free phenolic acid from complex of phenolic compound-carbohydrate or phenolic compound-protein during garlic aging at high temperature [7]. In addition, more polyphenol compounds can be produced from a non-enzymatic browning reaction during garlic aging [8]. Therefore, the presence of sulfurcontaining compounds, phenolic acids and flavonoids in black garlic should be important in preventing chronic disease. Nevertheless, all these bioactive compounds may undergo vaporization or degradation in vivo, resulting in a decrease of biological activity, especially for the highly volatile organosulfur compounds. To remedy this problem, the development of an appropriate technique such as nanoemulsion for encapsulation of bioactive compounds and enhancement of biological activity in vivo is extremely important.

Like garlic, it has been well documented that black garlic possesses many vital biological activities such as liver protection [9], anti-inflammation [10], and anti-cancer [11]. However, the effect of black garlic on the reduction of blood pressure and prevention of neurodegenerative disease using an animal model was less explored.

Dementia, a brain disease that frequently occurs for the elderly, can cause deterioration of cognition ability and memory. According to a report by Alzheimer's Disease International [12], the dementia population was estimated to be 50 million in 2018 and could reach a record high of 152 million in 2050 worldwide. Many factors have been shown to be associated with cognitive impairment, one of which is hypertension. However, the underlying mechanism remains unclear. It was suggested that the elevated blood pressure could lead to cerebrovascular remodeling [13]. When blood pressure is raised, the vascular wall smooth muscle hypertrophy will occur to decrease lumen diameter, resulting in vascular resistance increase and arteriosclerosis. Meanwhile, it can cause lesions of the aorta and arteriole, as well as white matter and gray matter in the brain, leading to cognitive impairment [13]. The objectives of this study were to use garlic as raw material to process into black garlic and determine bioactive compounds, including organosulfur compounds by GC-MS, as well as phenolic acids and flavonoids in both raw and black garlic by HPLCMS/MS. Then, both black garlic extracts and nanoemulsions were prepared to study and compare their inhibition effects on deoxycorticosterone acetate-salt-induced hypertension and its associated mild cognitive impairment in rats. A commercial drug lisinopril was also used for comparison.

\section{Materials and Methods}

\subsection{Reagents}

Standards of organic sulfur compounds including diallyl sulfide, diallyl disulfide, diallyl trisulfide, and internal standard isopropyl disulfide were procured from SigmaAldrich Co. (St. Louis, MO, USA). Both phenolic acid and flavonoid standards, including gallic acid, p-coumaric acid, and quercetin were also from Sigma-Aldrich Co.

The HPLC-grade solvent acetone was obtained from Merck Co. (Darmstadt, Germany). Deionized water was made using a Milli-Q water purification system from Millipore Co. (Bedford, MA, USA). The QuEChERS kit including extraction powder containing $4 \mathrm{~g}$ anhydrous magnesium sulfate plus $1 \mathrm{~g}$ anhydrous sodium acetate, and purification powder including $300 \mathrm{mg}$ primary and secondary amine (PSA), $900 \mathrm{mg}$ anhydrous magnesium sulfate plus $300 \mathrm{mg}$ C18EC (Octadecylsiloxane endcapped), ceramic homogenizer and 50-mL centrifuge tube was from Yu-Ho Co. (New Taipei City, Taiwan). Potassium dihydrogen phosphate, sodium chloride, potassium chloride, lisinopril, deoxycorticosterone acetate, 99\% ethanol, 1,1,3,3-tetra methoxy propane (TMP), trichloroacetic acid (TCA), and thiobarbituric acid (TBA) were also from Sigma-Aldrich Co. 


\subsection{Instrumentation}

Gas chromatograph (GC, model HP6890) coupled with a mass spectrometer (MS, model 5973) was from Agilent Technologies (Santa Clara, CA, USA). The UPLC system coupled with a triple quadrupole tandem mass spectrometer was from Thermo Fisher Scientific Co. (San Jose, CA, USA). Ultrasonicator (model DC400H) was from Hua-Hsiah Scientific Co. (Taipei, Taiwan). The centrifuge (5810R) was from Eppendorf Co. (Hauppauge, NY, USA). The microcentrifuge (Heraeus Fresco 21) was from Thermo Fisher Scientific Co. (San Jose, CA, USA). The nanoparticle size and zeta potential analyzer (SZ-100) was from Horiba Scientific Co. (Kyoto, Japan). The dynamic light scattering instrument was from Brookhaven Instruments Co. (Holtsville, NY, USA). The transmission electron microscope (TEM, model JEM-1400) was from JEOL Co. (Tokyo, Japan). The rotary evaporator (N1200A) was from Eyela Co. (Tokyo, Japan). The low-temperature circulating water tank (B402L) was from Firstek Co. (Taipei, Taiwan). The blood pressure gauge (BP-2000) was from Visitech System Co. (Apex, NC, USA).

\subsection{Processing of Garlic into Black Garlic}

Raw garlic was obtained from a local farm located at Yuan-Lin county in Taiwan. Its collection for use in this study is approved by Fu Jen Catholic University (New Taipei City, Taiwan) and exempted from any approval from local/national authorities owing to their use only for research purposes. The voucher specimen of raw garlic was deposited in herbarium of TAIwan Forestry Research Institute (TAIF, Taipei, Taiwan) and identified by Dr. Wen-Liang Chiou (TAIF) based on the accession number 04106. Then raw garlic was naturally aged in an incubator with temperature-controlled at $70{ }^{\circ} \mathrm{C}$ and relative humidity at $75 \%$ for 45 days, after which black garlic was collected for subsequent experiments. This aging condition was selected based on a report by Zhang et al. [14] suggesting that an appropriate aging temperature should be controlled at $70-80{ }^{\circ} \mathrm{C}$ with relative humidity at $80 \%$.

\subsection{Extraction and Purification of Organosulfur Compounds from Raw and Black Garlic by QuEChERS}

A QuEChERS method based on Chiu et al. [15] was modified to extract organosulfur compounds from raw and black garlic. Initially, 10 raw and 10 black garlic were each cut into pieces separately, pooled, and one gram was homogenized and poured into a 50-mL centrifuged tube, followed by adding one ceramic homogenizer, 10-mL deionized water and the mixture was shaken again for one min, followed by adding the extraction powder containing $4 \mathrm{~g}$ anhydrous magnesium sulfate and $1 \mathrm{~g}$ anhydrous sodium acetate, shaking the mixture vigorously for $1 \mathrm{~min}$ and centrifuging at $3200 \mathrm{~g}\left(4^{\circ} \mathrm{C}\right)$ for $10 \mathrm{~min}$. The supernatant $(4 \mathrm{~mL})$ was collected and poured into a centrifuged tube containing $900 \mathrm{mg}$ anhydrous magnesium sulfate, $300 \mathrm{mg}$ PSA and $300 \mathrm{mg}$ C18 EC for purification, followed by shaking the mixture for one min, centrifuging at $3200 \mathrm{~g}\left(4^{\circ} \mathrm{C}\right)$ for $10 \mathrm{~min}$, collecting the supernatant, filtering through a $0.22-\mu \mathrm{m}$ membrane filter and injecting for GC-MS analysis.

\subsection{GC-MS Analysis of Organosulfur Compounds in Raw and Black Garlic}

A GC-MS method based on Tocmo et al. [16] was modified to analyze organosulfur compounds in raw black garlic. A DM-5MS capillary column ( $30 \mathrm{~m} \times 0.25 \mathrm{~mm}$ ID, $0.25 \mu \mathrm{m}$ film thickness) was used to separate three organosulfur compounds within 40 min with $\mathrm{He}$ as carrier gas and flow rate at $1 \mathrm{~mL} / \mathrm{min}$, injector temperature $210{ }^{\circ} \mathrm{C}$, ion source temperature $200{ }^{\circ} \mathrm{C}$, interface temperature $270{ }^{\circ} \mathrm{C}$, injection volume $1 \mu \mathrm{L}$ and splitless mode with the following temperature programming condition: initial column temperature $50{ }^{\circ} \mathrm{C}$, maintained for $5 \mathrm{~min}$, increased to $210{ }^{\circ} \mathrm{C}$ at $5{ }^{\circ} \mathrm{C} / \mathrm{min}$ and maintained for three min. Both total ion chromatogram (TIC) and selected ion monitoring (SIM) were used for detection of organosulfur compounds with the scanning range from $0-600 \mathrm{~m} / \mathrm{z}$ for TIC, while for SIM, the detection was based on elution order of organosulfur compounds with the first group (5-10 min) for detection of diallyl sulfide with $m / z 73$, the second 
group (10-14 $\mathrm{min}$ ) for isopropyl disulfide (internal standard) with $m / z 108$, the third group (14-21 $\mathrm{min}$ ) for diallyl disulfide with $m / z$ 81, and the fourth group (21-48 min) for diallyl trisulfide with $m / z$ 73. In addition, the various organosulfur compounds in raw and black garlic were identified by comparison of retention time and mass spectra of unknown peaks with reference standards, as well as addition of reference standards to sample extract for co-chromatography.

For quantitation, a total of 6 concentrations $(1,5,10,15,20$ and $25 \mu \mathrm{g} / \mathrm{mL})$ were prepared separately for diallyl sulfide, diallyl disulfide and diallyl trisulfide. Then, for each concentration, the internal standard isopropyl disulfide with a fixed concentration at $10 \mu \mathrm{g} / \mathrm{mL}$ was mixed with each standard. The standard calibration curves were obtained by plotting concentration ratio (standard versus internal standard) against peak area ratio (standard versus internal standard), and the regression equation and coefficient of determination $\left(R^{2}\right)$ were obtained for each standard. Then the various organosulfur compounds in black garlic were quantified using the following formula:

Organosulfur compound $(\mu \mathrm{g} / \mathrm{g})=(\mathrm{As} / \mathrm{Ai}-\mathrm{b}) \times 1 / \mathrm{a} \times \mathrm{Ci} \times \mathrm{V} \times \mathrm{DF} \times 1 / \mathrm{R} \times 1 / \mathrm{Ws}$

where

As = peak area of organosulfur compounds

$\mathrm{Ai}=$ peak area of internal standard

$\mathrm{b}=$ intercept of the regression equation

$\mathrm{a}=$ slope of the regression equation

$\mathrm{Ci}=$ internal standard concentration $(\mu \mathrm{g} / \mathrm{mL})$

$\mathrm{V}=$ extract volume $(\mathrm{mL})$

$\mathrm{DF}=$ dilution factor

$\mathrm{R}=$ recovery $(\%)$

Ws = sample weight $(\mathrm{g})$

\subsection{Method Validation}

A total of 15 concentrations $(0.01,0.02,0.03,0.04,0.05,0.1,0.2,0.3,0.4,0.5,0.6,0.7$, $0.8,0.9$ and $1 \mu \mathrm{g} / \mathrm{mL}$ ) were prepared separately for each organosulfur standard and each concentration injected into GC-MS for determination of limit of detection (LOD) based on $\mathrm{S} / \mathrm{N} \geq 3$ and limit of quantitation (LOQ) based on $\mathrm{S} / \mathrm{N} \geq 10$. For the precision study, the intra-day variability was carried out by analyzing organosulfur compounds in black garlic in the morning, afternoon and evening on the same day with three triplicates for a total of 9 analyses. Similarly, the inter-day variability was performed by analyzing organosulfur compounds in black garlic in the morning, afternoon and evening on three different days for a total of 9 analyses. Both standard deviation (SD) and relative standard deviation (RSD, $\%)$ were calculated. For the recovery study, two levels of organosulfur standards, including diallyl sulfide (30 and $90 \mu \mathrm{g}$ ), diallyl disulfide ( 80 and $240 \mu \mathrm{g}$ ) and diallyl trisulfide (100 and $300 \mu \mathrm{g}$ ) were added to black garlic sample separately for extraction, purification and quantitation by GC-MS. The recovery was obtained by using the following formula:

Recovery $(\%)=\frac{\text { amount of organosulfur compounds found after GC }- \text { original amount by GC }}{\text { amount of organosulfur standards spiked }} \times 100$

\subsection{Determination of Phenolic Acids and Flavonoids in Raw and Black Garlic}

Two methods based on Kim, Kang and Gweon [8] and Kao et al. [17] were modified to determine total phenolic acids and total flavonoids, respectively. Initially, $30 \mathrm{~mL}$ of three different proportions of $50 \%, 70 \%$ and $95 \%$ ethanol in water were mixed separately with $3 \mathrm{~g}$ of raw or black garlic for comparison of extraction efficiency. Then the mixture was sonicated at $60^{\circ} \mathrm{C}$ for $1 \mathrm{~h}$ and centrifuged at $3200 \mathrm{~g}$ for $10 \mathrm{~min}\left(25^{\circ} \mathrm{C}\right)$. The supernatant was collected, filtered through a $0.6-\mu \mathrm{m}$ membrane filter, evaporated to dryness, dissolved in $10 \mathrm{~mL}$ of $70 \%$ ethanol and filtered through a $0.22-\mu \mathrm{m}$ membrane filter to obtain the extract. 
Then $30 \mu \mathrm{L}$ extract was collected and mixed with $120 \mu \mathrm{L}$ Folin-Ciocalteu reagent, after which the mixture was reacted in the dark for $5 \mathrm{~min}$, followed by adding $600 \mu \mathrm{L}$ sodium carbonate solution (15\%), mixing and reacting in the dark for $1 \mathrm{~h}$ and the absorbance was measured at $750 \mathrm{~nm}$. The content of total phenolic acids (expressed as gallic acid equivalent) was calculated based on the standard curve of gallic acid solution (in ethanol), which was obtained by plotting five different concentrations $(50,100,200,300$ and $400 \mu \mathrm{g} / \mathrm{mL}$ ) of gallic acid standard against absorbance.

Likewise, for total flavonoids determination, $500 \mu \mathrm{L}$ extract was collected and mixed with $30 \mu \mathrm{L}$ sodium nitrite solution (5\%), after which the mixture was left to stand at room temperature for $5 \mathrm{~min}$. Then $60 \mu \mathrm{L}$ aluminum chloride solution (10\%) was added, after which the solution was left to stand for $5 \mathrm{~min}$, followed by adding $300 \mu \mathrm{L}$ sodium hydroxide solution $(1 \mathrm{M})$ and $200 \mu \mathrm{L}$ chloroform, centrifuging, collecting the supernatant and measuring absorbance at $510 \mathrm{~nm}$. The content of total flavonoid (expressed as quercetin equivalent) was calculated based on the standard curve of quercetin, which was obtained by plotting 6 different concentrations of quercetin $(5,10,25,50,100$, and $200 \mu \mathrm{g} / \mathrm{mL})$ against absorbance.

For the determination of individual phenolic acids and flavonoids in raw and black garlic, a method based on Kim, Kang and Gweon [8] was modified. A 3-g raw or black garlic sample was mixed with $2.0 \mathrm{~g} / \mathrm{L}$ butylated hydroxyanisole (BHA) in methanol and $5 \mathrm{~mL}$ acetic acid solution (10\%). After mixing thoroughly, $15-\mathrm{mL}$ deionized water was added, followed by sonicating for $30 \mathrm{~min}$, adding $60 \mathrm{~mL}$ deionized water containing $22 \mathrm{mM}$ EDTA and $2 \%$ ascorbic acid, as well as $25 \mathrm{~mL}$ sodium hydroxide $(10 \mathrm{M})$. Then the solution was left at $30{ }^{\circ} \mathrm{C}$ for $30 \mathrm{~min}$, followed by adding $4 \mathrm{M}$ hydrochloric acid to adjust $\mathrm{pH}$ to 2 , repeating extraction with $15-\mathrm{mL}$ ethyl acetate three times. All the extracts were pooled, passed through anhydrous sodium sulfate, evaporated to dryness under nitrogen, dissolved in $2 \mathrm{~mL}$ methanol and filtered through a $0.22-\mu \mathrm{m}$ membrane filter for UPLC-MS/MS analysis [8]. Gallic acid, p-coumaric acid and quercetin were separated within $25 \mathrm{~min}$ by using an ACQUITY UPLC BEH C18 column $(100 \mathrm{~mm} \times 2.1 \mathrm{~mm}$ ID, $1.7 \mu \mathrm{m}$ particle size) with column temperature at $25{ }^{\circ} \mathrm{C}$, flow rate at $0.3 \mathrm{~mL} / \mathrm{min}$ and a gradient mobile phase of (A) $0.1 \%$ formic acid solution and (B) acetonitrile: $95 \% \mathrm{~A}$ and $5 \%$ $\mathrm{B}$ initially, changed to $85 \% \mathrm{~A}$ and $15 \% \mathrm{~B}$ in $7 \mathrm{~min}, 70 \% \mathrm{~A}$ and $30 \% \mathrm{~B}$ in $15 \mathrm{~min}, 100 \% \mathrm{~B}$ in $17 \mathrm{~min}$ and maintained for $8 \mathrm{~min}$.

A Dionex Ultimate 3000 model Open Sampler XRS UPLC System coupled with TSQ Quantiva triple quadrupole tandem mass spectrometer (Thermo Fisher Scientific Co, San Jose, CA, USA) with electrospray ionization (ESI) mode was used for detection of gallic acid, p-coumaric acid and quercetin with spray voltage at $3500 \mathrm{~V}$, collision gas at 1.5 arbitrary units, sweep gas flow rate at two arbitrary units, sheath gas flow rate at 38 arbitrary units, auxiliary gas flow rate at 12 arbitrary units, ion transfer tube temperature at $329^{\circ} \mathrm{C}$ and vaporizer temperature at $279^{\circ} \mathrm{C}$. Quantitation was carried out using the linear regression equations of the calibration curves of gallic acid, p-coumaric acid and quercetin standards prepared separately by plotting six concentrations of each standard $(1,5,10,25,50$ and $100 \mu \mathrm{g} / \mathrm{mL}$ ) against its corresponding peak area (quantitative ion intensity).

\subsection{Preparation of Black Garlic Nanoemulsion and Characteristic Determination}

Black garlic nanoemulsion was prepared from $70 \% \mathrm{EtOH}$ extract as it contains the highest level of total phenolic acids and total flavonoids. A portion $(1.25 \mathrm{~mL})$ of concentrated black garlic extract containing phenolic acids and flavonoids at $12,000 \mu \mathrm{g} / \mathrm{mL}$ was evaporated to dryness under nitrogen and $0.12 \mathrm{~g}$ grapeseed oil $(1.2 \%)$ was added and then stirred, followed by adding $0.8 \mathrm{~g}$ Tween $80(8 \%)$ and $0.2 \mathrm{~g}$ glycerol $(2 \%)$ for complete mixing. Then $8.88 \mathrm{~g}$ deionized water $(88.8 \%)$ was added, thoroughly mixed, and sonicated for $1 \mathrm{~h}$ to obtain a yellow-brown black garlic nanoemulsion with a transparent appearance.

The particle size and distribution of this black garlic nanoemulsion were analyzed by collecting a portion $(30 \mu \mathrm{L})$ and diluting 100 times with $25 \mathrm{mM}$ dihydrogen potassium phosphate buffer solution ( $\mathrm{pH}$ 5.3-5.5). Then this solution was filtered through a $0.45-\mu \mathrm{m}$ 
membrane filter and poured into a polystyrene colorimetric tube for determination of particle size and distribution by a dynamic light scattering analyzer (DLS) (90 plus model, Brookhaven Instruments Corp, Holtsville, NY, USA).

The zeta potential of this black garlic nanoemulsion was analyzed by collecting a portion $(10 \mu \mathrm{L})$ and then diluting 120 times with deionized water for determination at $25^{\circ} \mathrm{C}$ by a zeta potential analyzer (model SZ100, HORIBA Ltd., Kyoto, Japan).

Also, the particle size and shape of this black garlic nanoemulsion were analyzed by diluting 200 times with deionized water and a portion $(20 \mu \mathrm{L})$ was collected and dropped onto a carbon coated copper grid for standing for $30 \mathrm{~s}$. Then the excess sample was removed with a filter paper for negative staining with $20 \mu \mathrm{L}$ phosphotungstic acid $(2 \%)$ for $60 \mathrm{~s}$, followed by removing excess sample again with a filter paper and drying overnight in an oven for determination by a transmission electron microscope (TEM, model JEM 2100F, JOEL, Tokyo, Japan).

\subsection{Determination of Encapsulation Efficiency}

A portion $(100 \mu \mathrm{L})$ of the black garlic nanoemulsion was collected, diluted 10 times with $25 \mathrm{mM}$ dihydrogen potassium phosphate buffer solution ( $\mathrm{pH}$ 5.3-5.5) and poured into a centrifuge tube containing a dialysis membrane $(3 \mathrm{kDa})$ for centrifugation at $12,000 \mathrm{rpm}$ for $20 \mathrm{~min}\left(25^{\circ} \mathrm{C}\right)$. Then the lower layer was collected for determination of free (unencapsulated) phenolic acids and flavonoids (gallic acid + p-coumaric acid + quercetin) by using the following formula:

Encapsulation efficiency $(\%)=\frac{\text { total amount of phenolic acids and flavonoids }- \text { amount of free phenolic acids and flavonoids }}{\text { total amount of phenolic acids and flavonoids }} \times 100$

\subsection{Stability Study}

The black garlic nanoemulsion was stored at $4{ }^{\circ} \mathrm{C}$ for three months, during which a portion of the sample was collected every seven days for determination of particle size, distribution and zeta potential. Similarly, a sample $(200 \mu \mathrm{L})$ of black garlic nanoemulsion was heated in a water bath for $0.5,1,1.5$ and $2 \mathrm{~h}$ separately with temperatures controlled at $40,60,80$ and $100{ }^{\circ} \mathrm{C}$.

\subsection{Animal Study}

A total of 42 6-week-old Wistar male rats were purchased from Taiwan BioLASCO Co (Taipei, Taiwan), and these animals were housed in individual ventilation cages with the temperature at $21 \pm 2{ }^{\circ} \mathrm{C}$ and relative humidity at $55 \pm 10 \%$ for $12 \mathrm{~h}$ under light in Fu Jen University Animal Center. This animal experiment was approved by Fu Jen University animal subjects review committee, while the methods involving animal experiments were performed based on the approved guidelines [18]. All the rats were fed with a laboratory rodent diet (LabDiet Co, St Louis, MO, USA) and water ad libitum. The body weight and water intake of each mouse were measured every week for a total of six weeks. After the rats were acclimatized for two weeks, the eight-week-old rats with an average weight of about $256 \mathrm{~g}$ were ready for experiments. Then a total of 42 rats were divided into seven groups with 6 each for administration of the followings for 14 weeks: (1) C (control group), sterilized water $(0.3 \mathrm{~mL})$ with subcutaneous injection twice a week for 14 weeks; (2) D (induction group), deoxycorticosterone acetate (DOCA)-salt with subcutaneous injection at $25 \mathrm{mg} / \mathrm{kg} \mathrm{BW}(0.3 \mathrm{~mL})$ twice a week for 14 weeks, while sterilized water $(2 \mathrm{~mL})$ containing sodium chloride $(1 \%)$ and potassium chloride $(0.2 \%)$ was provided for 14 weeks for induction of hypertension in rats; (3) PC (positive control group), DOCA-salt with subcutaneous injection at $25 \mathrm{mg} / \mathrm{kg}$ BW $(0.3 \mathrm{~mL})$ twice a week for 14 weeks and tube feeding of lisinopril (hypotensive drug) at $15 \mathrm{mg} / \mathrm{kg}$ BW once every day for the last seven weeks; (4) HE (high-dose extract group), DOCA-salt with subcutaneous injection at $25 \mathrm{mg} / \mathrm{kg}$ BW $(0.3 \mathrm{~mL})$ twice a week for 14 weeks and tube feeding of black garlic extract at $100 \mathrm{mg} / \mathrm{kg} \mathrm{BW} \mathrm{(6} \mathrm{mg} \mathrm{of} \mathrm{total} \mathrm{phenolic} \mathrm{acids)} \mathrm{once} \mathrm{every} \mathrm{day} \mathrm{for} \mathrm{the} \mathrm{last} \mathrm{seven}$ weeks; (5) HN (high-dose nanoemulsion group), DOCA-salt with subcutaneous injection 
at $25 \mathrm{mg} / \mathrm{kg}$ BW twice $(0.3 \mathrm{~mL})$ a week for 14 weeks and tube feeding of black garlic nanoemulsion at $100 \mathrm{mg} / \mathrm{kg}$ BW (6 mg of total phenolic acids) once every day for the last seven weeks; (6) LE (low-dose extract group), DOCA-salt with subcutaneous injection at $25 \mathrm{mg} / \mathrm{kg}$ BW $(0.3 \mathrm{~mL})$ twice a week for 14 weeks and tube feeding of black garlic extract at $50 \mathrm{mg} / \mathrm{kg}$ BW (3 mg of total phenolic acids) once every day for the last seven weeks; (7) LN (low-dose nanoemulsion group), DOCA-salt with subcutaneous injection at $25 \mathrm{mg} / \mathrm{kg}$ BW $(0.3 \mathrm{~mL})$ twice a week for 14 weeks and tube feeding of black garlic nanoemulsion at $50 \mathrm{mg} / \mathrm{kg} \mathrm{BW} \mathrm{(3} \mathrm{mg} \mathrm{of} \mathrm{total} \mathrm{phenolic} \mathrm{acids)} \mathrm{once} \mathrm{every} \mathrm{day} \mathrm{for} \mathrm{the} \mathrm{last} \mathrm{seven} \mathrm{weeks.}$ The blood pressure of each rat was measured once every two weeks. Like D group, all the groups, including PC, HE, HN, LE, and LN, also received sterilized water (2 mL) containing sodium chloride (1\%) and potassium chloride (0.2\%) for 14 weeks.

\subsection{Morris Water Maze Test}

Two methods based on Morris [19] and Sun et al. [20] were used for the evaluation of memory and learning ability of rats. This test started at the 13th week after feeding and was conducted for seven days with the first three for reference memory test (long-term memory), the fourth day for spatial exploration and the last three for working memory test (short-term memory). The Morris water maze is composed of a round swimming pool with a diameter of $160 \mathrm{~cm}$ and height of $60 \mathrm{~cm}$, as well as an escape platform with diameter of $10 \mathrm{~cm}$ and a height of $29 \mathrm{~cm}$. Prior to test, water $\left(25^{\circ} \mathrm{C}\right)$ was added to a depth of $30 \mathrm{~cm}$ and the platform was below the water surface. The swimming pool was divided into four quadrants (I, II, III and IV) with five different entry points. According to the test difference, the escape platform was placed at the central point of a specific quadrant, while the different shapes of marks (square, triangle, round and cross) were on the swimming pool wall for distinguishing orientation by rats. In addition, a camera was used to record the swimming path of rats.

The reference memory test was carried out from day 84 to day 86 . The escape platform was fixed at the central point of the 1st quadrant and rats could enter into water from five entry points randomly. Rats were trained five times with $90 \mathrm{~s}$ each every day. If rats could find the escape platform within $90 \mathrm{~s}$, the rats must rest on the platform for $30 \mathrm{~s}$, back to cage for another $30 \mathrm{~s}$ before starting the next test. Conversely, if rats could not find the escape platform within $90 \mathrm{~s}$, they must be guided to the escape platform for rest for $30 \mathrm{~s}$, back to cage for another $30 \mathrm{~s}$ before starting the next test. This test lasted three days, during which the swimming path and time length of the rats were recorded.

On day 87 , the spatial probe test was performed by removing the escape platform from the swimming pool, while rats faced the pool wall and entered into the water from the quadrant IV for swimming for $90 \mathrm{~s}$. The time length spent in the quadrant I and path of full swimming of rats were recorded.

On day 88 to day 90, the working memory test was conducted by placing the escape platform on the central point of different quadrants (II, III and IV), and the rats could enter into water from five entry points randomly. Rats were trained five times with $90 \mathrm{~s}$ each every day. If rats could find the escape platform within $90 \mathrm{~s}$, the rats must rest on the platform for $15 \mathrm{~s}$, back to the cage for another $60 \mathrm{~s}$ before starting the next test. However, if rats could not find the escape platform within $90 \mathrm{~s}$, they must be guided to the escape platform for rest for $15 \mathrm{~s}$, back to cage for another $60 \mathrm{~s}$ before starting the next test. This test lasted three days, during which the swimming path and the time length of rats were recorded.

After the feeding period ended, rats were suffocated with carbon dioxide and then sacrificed. Blood was collected from the celiac vein by a needle, then five $\mathrm{mL}$ was collected into a tube without anticoagulant and stood still for $20 \mathrm{~min}$, followed by centrifuging at $3200 \mathrm{~g}$ for $10 \mathrm{~min}\left(4^{\circ} \mathrm{C}\right)$ and collecting the supernatant (serum) for storage at $-80{ }^{\circ} \mathrm{C}$. Meanwhile, 5-mL blood was collected into a tube containing the anticoagulant tri-potassium ethylenediaminetetraacetic acid (K3 EDTA) and stood still for $20 \mathrm{~min}$, followed by centrifuging and collecting the upper layer (plasma) for storage at $-80^{\circ} \mathrm{C}$. After blood collection, 
various organs including the heart, liver, kidney, lung and brain were collected, weighed, and stored at $-80{ }^{\circ} \mathrm{C}$ for further analysis. For the brain organ, the hippocampus part was collected and then $0.1 \mathrm{~g}$ mixed with $1 \mathrm{~mL}$ of $25 \mathrm{mM}$ phosphoric acid buffer solution ( $\mathrm{pH}$ 7.4). After homogenization, this solution was centrifuged at $12,000 \mathrm{~g}$ for $30 \mathrm{~min}\left(4^{\circ} \mathrm{C}\right)$ and then the supernatant was collected for storage at $-80^{\circ} \mathrm{C}$ for further analysis.

\subsection{Biochemical Analysis of Blood}

Both angiotensin II and bradykinin were analyzed respectively using a commercial ELISA kit EKE-002-12 and EK-009-01 (Phoenix Pharmaceuticals Inc, Burlingame, CA, USA). Aldosterone was also analyzed using a commercial radioimmunoassay kit (DSL-8600, Beckman Coulter, Brea, CA, USA). Nitric oxide (NO) was analyzed using a commercial kit (780001, Cayman Chemical Co, Ann Arbor, MI, USA).

\subsection{Determination of Oxidative Index in Brain Tissue}

A method based on Hodges et al. [21] was used to determine malondialdehyde (MDA) content in brain tissue. A $100-\mu \mathrm{L}$ brain sample or seven different concentrations $(5,10,20$, $25,50,75$ and $100 \mu \mathrm{M}$ of the standard 1,1,3,3-tetramethoxypropane (TMP) were mixed separately with $200 \mu \mathrm{L} \mathrm{10 \%}$ trichloroacetic acid (TCA), after which each mixture was reacted on ice for $15 \mathrm{~min}$ to precipitate protein, followed by centrifuging at $3200 \mathrm{~g}$ for $15 \mathrm{~min}\left(4^{\circ} \mathrm{C}\right)$, collecting $200 \mu \mathrm{L}$ supernatant, adding $200 \mu \mathrm{L}$ of $0.67 \%$ thiobarbituric acid (TBA), reacting in a water bath $\left(100^{\circ} \mathrm{C}\right)$ for $10 \mathrm{~min}$ and measuring absorbance at $535 \mathrm{~nm}$ for MDA quantitation based on the standard curve.

The superoxide dismutase (SOD) activity was determined using a commercial kit (RANSOD-SD125, Randox Laboratories Ltd., Antrim, UK). The catalase activity was determined using a commercial kit (707002, Cayman Chemical Co, Ann Arbor, MI, USA). The glutathione content was determined using a commercial kit (703002, Cayman Chemical Co, Ann Arbor, MI, USA). The glutathione peroxidase (GSH-Px) activity was determined using a commercial kit (703102, Cayman Chemical Co, Ann Arbor, MI, USA). The acetylcholinesterase (AChE) activity was determined using a commercial kit (ab138871, Abcam Plc, MA, USA).

\subsection{Determination of Inflammation Index in Brain Tissue}

The content of tumor necrosis factor (TNF- $\alpha$ ) was determined using a commercial ELISA kit (438207, Biolegend Inc, San Diego, CA, USA). The content of interleukin-1 $\beta$ (IL-1 $\beta$ ) was determined using a commercial ELISA kit (900-K91, Pepro Tech Inc, Rocky Hill, NJ, USA). The content of interleukin-6 (IL-6) was determined using a commercial ELISA kit (437107, Biolegend Inc, San Diego, CA, USA).

\subsection{Statistical Analysis}

All the data were subjected to analysis by using Statistical Analysis System [22]. In addition, the variance analysis was conducted by ANOVA, and Duncan's multiple range test was used for a significant difference in mean comparison $(p<0.05)$.

\section{Results and Discussion}

\subsection{Analysis of Organosulfur Compounds in Raw and Black Garlic by GC-MS}

Figure 1A shows the GC-MS chromatogram of organosulfur compounds in black garlic. Based on the identification criteria shown in the method section, three organosulfur compounds, including diallyl sulfide, diallyl disulfide and diallyl trisulfide were identified in black garlic, with retention time being 6.62, 14.57 and $22.83 \mathrm{~min}$, respectively. Isopropyl disulfide with a retention time at 12.13 min was used as an internal standard to quantify the three organosulfur compounds, with the contents of diallyl sulfide, diallyl disulfide and diallyl trisulfide in black garlic being 87.8, 203.9 and $282.6 \mu \mathrm{g} / \mathrm{g}$, respectively, based on triplicate determinations (Table 1A). However, in raw garlic, the levels of diallyl sulfide, diallyl disulfide and diallyl trisulfide were $0.93,2.51$ and $3.49 \mu \mathrm{g} / \mathrm{g}$, respectively. This 
outcome implied that the level of organosulfur compounds in black garlic was much higher than in raw garlic (Table 1A). The regression equations of the standard calibration curves for diallyl sulfide, diallyl disulfide and diallyl trisulfide were $y=1.4786 x-0.799$, $\mathrm{y}=0.4217 \mathrm{x}-0.1456$ and $\mathrm{y}=0.6931 \mathrm{x}-0.2015$, respectively, with $\mathrm{R}^{2}$ being all higher than 0.98 . For the intra-day variability determination, the RSD (\%) for diallyl sulfide, diallyl disulfide and diallyl trisulfide were 3.01, 2.73 and 3.75, respectively, while for the inter-day variability, the RSD (\%) were 2.72, 4.77 and 6.67, respectively. All the precision data meets the regulation issued by Taiwan Food and Drug Administration (TFDA) [23], stating that the RSD should be less than $10 \%$ when the analyte concentration $\geq 1 \mathrm{ppm}$ for both the intra-day and the inter-day variability.
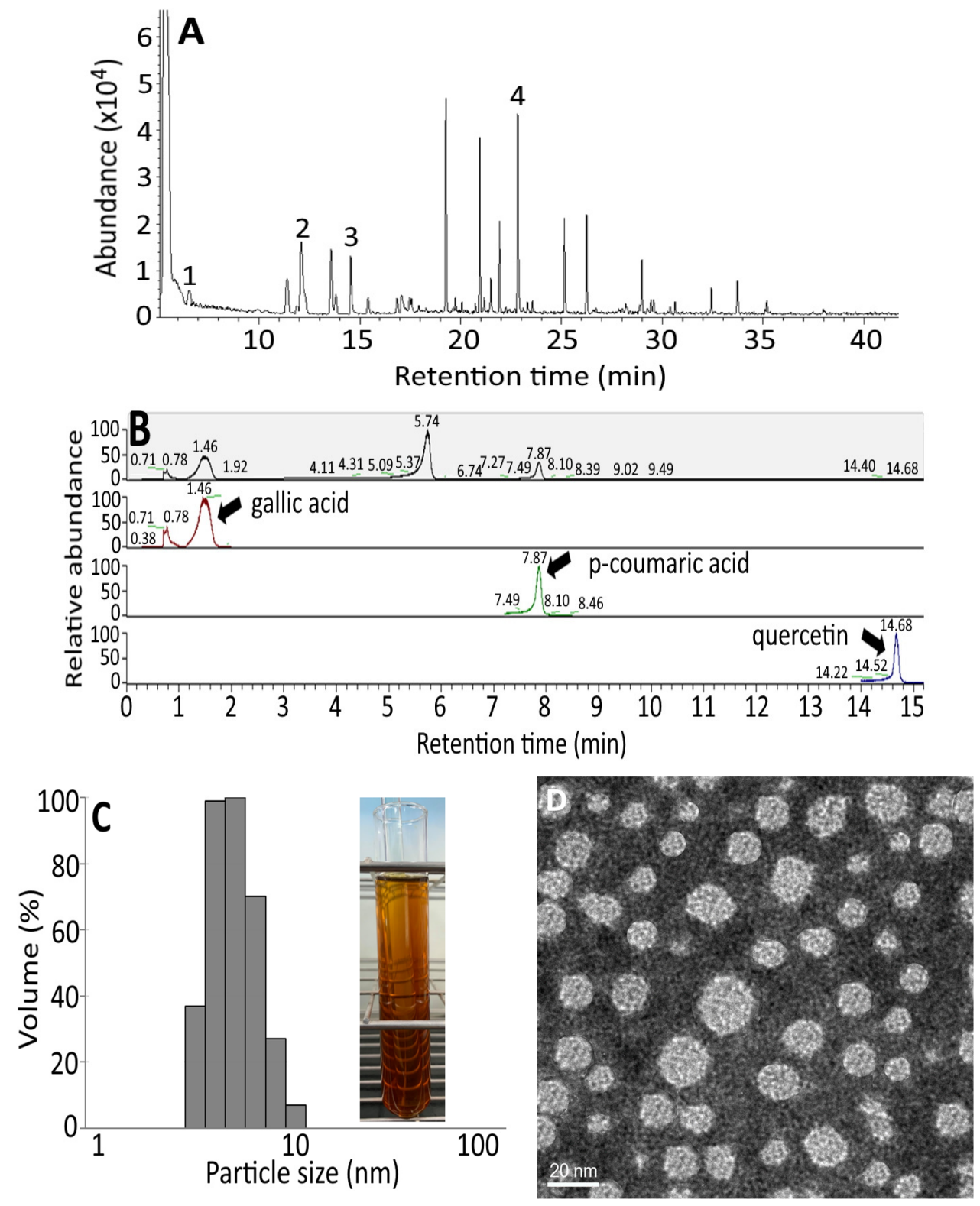

Figure 1. GC-MS chromatogram of black garlic extract using a DB-5MS column (A) and UPLC-MS/MS chromatograms of phenolic acid and flavonoids in black garlic with total ion chromatogram shown on the top and the other three being SRM chromatograms (B) as well as the particle size distribution of black garlic nanoemulsion by a dynamic light scattering method along with an inset showing its appearance (C) and transmission electron microscopic image (D). Peaks: 1, diallyl sulfide (DAS); 2, isopropyl disulfide (internal standard); 3, diallyl disulfide (DADS); 4, diallyl trisulfide (DATS). 
Table 1. (A) Contents ( $\mu \mathrm{g} / \mathrm{g}$ ) of organosulfur compounds in raw and black garlic by GC-MS analysis. (B) Effect of different ethanol proportion on the contents of total phenolic acids and total flavonoids in raw and black garlic by UPLCMS/MS analysis.

\begin{tabular}{|c|c|c|c|c|c|c|}
\hline \multicolumn{7}{|c|}{ (A) } \\
\hline & \multicolumn{2}{|c|}{ Diallyl Sulfide } & \multicolumn{2}{|c|}{ Diallyl Disulfide } & \multicolumn{2}{|c|}{ Diallyl Trisulfide } \\
\hline Raw garlic & \multicolumn{2}{|c|}{$0.93^{c}$} & \multicolumn{2}{|c|}{$2.51^{b}$} & \multicolumn{2}{|c|}{$13.49^{\mathrm{a}}$} \\
\hline Black garlic & \multicolumn{2}{|c|}{$87.8^{\mathrm{c}}$} & \multicolumn{2}{|c|}{$203.9^{b}$} & \multicolumn{2}{|c|}{$282.6^{\mathrm{a}}$} \\
\hline \multicolumn{7}{|c|}{ (B) } \\
\hline & \multicolumn{2}{|c|}{$50 \%$ EtOH } & \multicolumn{2}{|c|}{$70 \% \mathrm{EtOH}$} & \multicolumn{2}{|c|}{ 95\% EtOH } \\
\hline & Raw Garlic & Black Garlic & Raw Garlic & Black Garlic & Raw Garlic & Black Garlic \\
\hline Total phenolic acids A & $0.590 \pm 0.049^{\mathrm{e}}$ & $5.49 \pm 0.35^{b}$ & $0.641 \pm 0.023^{d}$ & $6.75 \pm 0.46^{\mathrm{a}}$ & $0.534 \pm 0.024^{\mathrm{f}}$ & $1.40 \pm 0.05^{\mathrm{c}}$ \\
\hline Total flavonoids $B$ & $0.044 \pm 0.006^{\mathrm{e}}$ & $0.75 \pm 0.05^{b}$ & $0.120 \pm 0.010^{\mathrm{d}}$ & $1.28 \pm 0.12^{\mathrm{a}}$ & $0.025 \pm 0.006^{\mathrm{f}}$ & $0.15 \pm 0.01^{\mathrm{c}}$ \\
\hline
\end{tabular}

The LOD were $0.1,0.2$ and $0.04 \mu \mathrm{g} / \mathrm{mL}$ for diallyl sulfide, diallyl disulfide and diallyl trisulfide, respectively, while the LOQ were $0.4,0.6$ and $0.15 \mu \mathrm{g} / \mathrm{mL}$. For the accuracy study, the recoveries for diallyl sulfide, diallyl disulfide and diallyl trisulfide were $89.7,93.5 \%$ and $91.1 \%$, respectively. The recovery data also meets the regulation issued by TFDA [23], stating that the recovery should be from $85-110 \%$ when the analyte concentration $\geq 100 \mathrm{ppm}$. All the data revealed that the method employed in this study for the determination of organosulfur compounds in black garlic possessed high precision and accuracy. In several previous studies, Locatelli et al. [24] reported that diallyl trisulfide was present in the highest amount in home-cooked garlic, followed by diallyl disulfide and diallyl sulfide. However, Tocmo et al. [25] reported that during cooking, allicin could be converted to diallyl disulfide and diallyl trisulfide, both of which may undergo volatilization following prolonged cooking. Zhang et al. [26] further pointed out that the allicin level could decrease during black garlic aging, accompanied by the formation of diallyl disulfide and diallyl trisulfide at high temperature because of allicin instability. Thus, in our study the presence of a high level of diallyl trisulfide, diallyl disulfide and diallyl sulfide in black garlic should be due to the conversion of allicin during aging.

\subsection{Analysis of Phenolic Acids and Flavonoids in Raw and Black Garlic}

Table 1B shows the effect of different ethanol proportion on the contents of total phenolic acids and total flavonoids in raw and black garlic. With $70 \%$ ethanol as the extraction solvent, the highest level of total phenolic acids $(6.75 \mathrm{mg} / \mathrm{g})$ expressed as gallic acid equivalent (GAE) and total flavonoids $(1.28 \mathrm{mg} / \mathrm{g}$ ) expressed as quercetin equivalent (QE) was shown in black garlic, followed by $50 \%$ ethanol and $95 \%$ ethanol. A similar trend was shown for raw garlic. In several previous studies, Purev et al. [27] also showed with $70 \%$ ethanol as the extraction solvent, the highest yield of total phenolics was obtained in black garlic. In another study, Thach and Thuy [28] also reported that black garlic contained total phenolics and total flavonoids at $7.94 \mathrm{mg} \mathrm{GAE} / \mathrm{g}$ and $3.37 \mathrm{mg} \mathrm{QE} / \mathrm{g}$, respectively. However, a lower level of total phenolics $(0.98 \mathrm{mg} \mathrm{GAE} / \mathrm{g})$ and total flavonoids $(0.87 \mathrm{mg}$ $\mathrm{QE} / \mathrm{g}$ ) in black garlic was reported by Kim, Kang and Gweon [8]. This difference may be accounted for by the difference in aging temperature and relative humidity, time length of aging, garlic variety and solvent variety. By comparison, the levels of total phenolic acids and total flavonoids were much higher in black garlic than in raw garlic (Table 1B), probably caused by the decomposition of the complex of phenolics-protein or phenolicscarbohydrate for the release of free phenolic acids. In addition, the polyphenol compounds may be produced from non-enzymatic browning reaction during aging $[7,8]$.

Figure 1B shows the UPLC-MS/MS chromatograms of phenolic acids and flavonoids in black garlic with total ion chromatogram on the top and selective reaction monitor- 
ing (SRM) mode for the other three chromatograms. Of the various phenolic acids and flavonoids, gallic acid, p-coumaric acid and quercetin were identified and quantified with a level of $19.19,27.03$ and $22.77 \mu \mathrm{g} / \mathrm{g}$, respectively. A similar content of gallic acid $(18.65 \mu \mathrm{g} / \mathrm{g}), \mathrm{p}$-coumaric acid $(29.51 \mu \mathrm{g} / \mathrm{g})$ and quercetin $(7.31 \mu \mathrm{g} / \mathrm{g})$ in black garlic was also reported by Kim, Kang and Gweon [8] However, Martínez-Casas, Lage-Yusty and López-Hernández [6] reported a low level of p-coumaric acid $(7.5 \mu \mathrm{g} / \mathrm{g})$ in black garlic, probably caused by the difference in aging condition of the garlic and garlic variety. Compared to black garlic, a much lower level of gallic acid, p-coumaric acid and quercetin was present in raw garlic, which equal to $3.27,2.25$, and $2.06 \mu \mathrm{g} / \mathrm{g}$, respectively. Thus, black garlic nanoemulsion was prepared for subsequent experiments.

\subsection{Characteristic of Black Garlic Nanoemulsion}

Figure $1 \mathrm{C}$ shows the particle size distribution of black garlic nanoemulsion along with an inset depicting its deep-orange and transparent appearance with an average particle size of $10.8 \mathrm{~nm}$, polydispersity index (PDI) of 0.135 and zeta-potential of $-60.7 \mathrm{mV}$ (Figure 1C and Table S1). This outcome implied that a narrow distribution of nanoparticles and a high stability of this black garlic nanoemulsion was attained as it was reported that with the PDI value from 0.1 to 0.25 , the particle size distribution could be even and narrow in a nanosystem [29]. In addition, with the zeta potential $>30 \mathrm{mV}$ or $<-30 \mathrm{mV}$, high stability can be obtained for a nanosystem [29]. Compared to some other nanoemulsions prepared by Mahdi et al. [30] and Baccarin and Lemos-Senna [31], our study showed a much lower PDI and zeta potential, demonstrating a high stability of this black garlic nanoemulsion.

The encapsulation efficiency of the black garlic nanoemulsion was calculated to be $83.2 \%$ based on the total phenolic compounds containing gallic acid, p-coumaric acid and quercetin. The content of organosulfur compounds in black garlic nanoemulsion was not used for the determination of encapsulation efficiency mainly because of its volatility, which may undergo loss during the nanoemulsion preparation. This outcome is similar to a study by Bazana et al. [32], preparing a Physalis peruviana calyx nanoemulsion composed of middle-chain triglyceride, Span 80, Tween 80 , and deionized water, and reporting an encapsulation efficiency of $84.1 \%$.

Figure 1D shows a TEM image of black garlic nanoemulsion, and an average particle size of $14 \mathrm{~nm}$ with a round shape was obtained, which is similar to that $(10.8 \mathrm{~nm})$ measured by DLS. This size is much smaller than the study by Mahdi, Noor, Sakeena, Abdullah, Abdulkarim and Sattar [30], preparing total phenolics nanoemulsion from Phyllanthus urinaria and reporting an average particle size of $30.74 \mathrm{~nm}$.

Table S1 shows particle size, PDI and zeta potential of black garlic nanoemulsion over a 90-day storage period at $4{ }^{\circ} \mathrm{C}$. Only a minor change in particle size, PDI and zeta potential was shown during storage, implying a high stability of the black garlic nanoemulsion prepared in our study. Similarly, this black garlic nanoemulsion also showed a high stability during heating at $40,60,80$ and $100{ }^{\circ} \mathrm{C}$ for $0.5,1$ and $2 \mathrm{~h}$, as evident by a slight change in particle size and PDI (Table S2). However, the zeta potential increased to $>-30 \mathrm{mV}$ when the temperature was $\geq 80^{\circ} \mathrm{C}$ and heating time $\geq 1 \mathrm{~h}$, indicating that the heating condition should be controlled carefully to obtain the highest stability of this black garlic nanoemulsion.

\subsection{Animal Study}

Table S3 shows the effect of the administration of black garlic extract and nanoemulsion on body weight in DOCA-salt-induced hypertension and its associated mild cognitive impairment in rats. A time-dependent increase in the body weight of rats was observed over a 13-week feeding period for all the groups. Compared to $C$ (control) group, the body weight in rats for $\mathrm{D}, \mathrm{PC}, \mathrm{HE}, \mathrm{HN}, \mathrm{LE}$ and LN groups were significantly lower $(p<0.05)$ by $11.5 \%, 11.9 \%, 11.9 \%, 9.1 \%, 8.2 \%$ and $12.1 \%$, respectively. However, there was no significant difference $(p>0.05)$ in body weight of rats between $\mathrm{D}$ and the other five groups (PC, HE, $\mathrm{HN}, \mathrm{LE}$ and LN). The daily water intake showed an inconsistent change over a 13-week 
feeding period for all the groups (Table S4). Compared to $C$ group on week 13, the water intake by rats for $\mathrm{D}, \mathrm{PC}, \mathrm{HE}, \mathrm{HN}, \mathrm{LE}$ and LN groups were significantly higher $(p<0.05)$ by 3.23-, 3.59-, 3.45-, 3.64-, 3.43- and 3.48-fold, respectively. However, there was no significant difference $(p>0.05)$ in water intake between $\mathrm{D}$ and the other five groups (PC, HE, $\mathrm{HN}$, $\mathrm{LE}$ and LN). This result is expected as both sodium chloride and potassium chloride were added to drinking water and hence the water demand for $\mathrm{D}$ and the other five groups should be enhanced greatly. In addition, DOCA, a kind of mineral corticoid, can not only combine with its receptor to enhance sodium retention and potassium excretion for maintenance of body balance but also stimulate salt appetite in rats to increase saltwater intake [33,34].

Table 2 shows the effect of the administration of black garlic extract and nanoemulsion on systolic blood pressure in DOCA-salt-induced hypertension and its associated mild cognitive impairment in rats. Initially there was no significant difference $(p>0.05)$ in systolic blood pressure in rats between $C$ and the other 6 groups. However, this difference became more pronounced after the feeding time reached 4 weeks. Following 8-week administration, the systolic blood pressure in rats for D, PC, HE, HN, LE and LN groups were significantly higher $(p<0.05)$ than $C$ group by $49.9,41.0,44.5,42.8,44.5$ and $42.7 \mathrm{mmHg}$, respectively, indicating that a high-blood-pressure animal model was successfully established on week 8. Following administration for another 4 weeks (week 12), the systolic blood pressure in rats could be reduced by 29.0, 23.4, 24.0, 28.4 and $21.1 \mathrm{mmHg}$ for PC, HE, HN, LE and LN groups, respectively, compared to D group. This finding clearly revealed that the hypotensive drug lisinopril and both high-dose black garlic extract and nanoemulsion were the most effective in reducing blood pressure in DOCA-salt-induced rats. Thus, an optimal dose of black garlic extract and nanoemulsion is required to reduce systolic blood pressure in DOCA-salt-induced rats.

Table 2. Effect of the administration of black garlic extract and nanoemulsion on systolic blood pressure in DOCA-saltinduced hypertension and its associated mild cognitive impairment in rats.

\begin{tabular}{|c|c|c|c|c|c|c|c|}
\hline \multirow{2}{*}{ Groups } & \multicolumn{7}{|c|}{ Systolic Blood Pressure (mmHg) } \\
\hline & Week 0 & Week 2 & Week 4 & Week 6 & Week 8 & Week 10 & Week 12 \\
\hline $\mathrm{C}$ & $117.2 \pm 3.5^{\mathrm{Ba}}$ & $121.4 \pm 3.6^{\mathrm{ABb}}$ & $120.3 \pm 6.4^{\mathrm{ABb}}$ & $123.2 \pm 3.9^{\mathrm{Ab}}$ & $117.0 \pm 4.9^{\mathrm{Bc}}$ & $119.2 \pm 4.2^{\mathrm{ABC}}$ & $120.2 \pm 4.9^{\mathrm{ABd}}$ \\
\hline $\mathrm{D}$ & $118.5 \pm 2.9^{\mathrm{Ea}}$ & $126.0 \pm 4.0^{\mathrm{Dab}}$ & $137.5 \pm 6.3^{\mathrm{Ca}}$ & $160.0 \pm 6.3^{\mathrm{Ba}}$ & $166.9 \pm 5.1^{\mathrm{Aa}}$ & $169.5 \pm 7.7^{\mathrm{Aa}}$ & $173.4 \pm 4.4^{\mathrm{Aa}}$ \\
\hline PC & $120.5 \pm 4.8^{\mathrm{Da}}$ & $127.7 \pm 6.6^{\mathrm{Cab}}$ & $138.4 \pm 8.2^{\mathrm{Ba}}$ & $158.3 \pm 5.7 \mathrm{Aa}$ & $158.0 \pm 4.6^{\mathrm{Ab}}$ & $152.6 \pm 6.9^{\mathrm{Ab}}$ & $144.4 \pm 7.3^{\mathrm{Bc}}$ \\
\hline $\mathrm{HE}$ & $119.4 \pm 4.5^{\mathrm{Da}}$ & $125.6 \pm 6.5^{\mathrm{Dab}}$ & $136.8 \pm 9.5^{\mathrm{Ca}}$ & $157.2 \pm 9.0 \mathrm{ABa}$ & $161.5 \pm 7.7^{\mathrm{Aab}}$ & $156.7 \pm 6.6^{\mathrm{ABb}}$ & $150.0 \pm 7.6^{\mathrm{Bbc}}$ \\
\hline $\mathrm{HN}$ & $118.6 \pm 3.6^{\mathrm{Ea}}$ & $129.0 \pm 5.8^{\mathrm{Da}}$ & $141.3 \pm 4.9^{\mathrm{Ca}}$ & $158.7 \pm 7.0^{\mathrm{Aa}}$ & $159.8 \pm 8.7^{\mathrm{Aab}}$ & $155.2 \pm 6.8^{\mathrm{Ab}}$ & $149.4 \pm 8.1^{\mathrm{Bbc}}$ \\
\hline LE & $116.8 \pm 5.1^{\mathrm{Da}}$ & $124.8 \pm 8.5^{\mathrm{Cab}}$ & $144.5 \pm 6.7^{\mathrm{Ba}}$ & $162.7 \pm 6.5^{\mathrm{Aa}}$ & $161.5 \pm 6.7^{\mathrm{Aab}}$ & $158.2 \pm 8.0^{\mathrm{Ab}}$ & $155.0 \pm 8.0^{\mathrm{Ab}}$ \\
\hline $\mathrm{LN}$ & $119.1 \pm 6.0^{\mathrm{Da}}$ & $129.5 \pm 5.6^{\mathrm{Ca}}$ & $142.1 \pm 6.3^{\mathrm{Ba}}$ & $160.2 \pm 7.1^{\mathrm{Aa}}$ & $159.7 \pm 7.3^{\mathrm{Aab}}$ & $156.3 \pm 8.2^{\mathrm{Ab}}$ & $152.3 \pm 5.3^{\mathrm{Abc}}$ \\
\hline
\end{tabular}

Data are presented as means \pm standard deviation $(n=6)$; C, control; D, DOCA-salt at a dose $25 \mathrm{mg} / \mathrm{kg} \mathrm{BW}$; PC, DOCA-salt with the administration of lisinopril at a dose $15 \mathrm{mg} / \mathrm{kg}$ BW; HE, DOCA-salt with the administration of black garlic extract at a dose of $100 \mathrm{mg} / \mathrm{kg} \mathrm{BW} ; \mathrm{HN}$, DOCA-salt with the administration of black garlic nanoemulsion at a dose of $100 \mathrm{mg} / \mathrm{kg}$ BW; LE, DOCA-salt with the administration of black garlic extract at a dose of $50 \mathrm{mg} / \mathrm{kg}$ BW; LN, DOCA-salt with the administration of black garlic nanoemulsion at a dose of $50 \mathrm{mg} / \mathrm{kg}$ BW. Values with different capital letters (A-E) in the same row and small letters (a-d) in the same column are significantly different $(p<0.05)$.

In the literature, most studies deal with the effect of raw garlic extract, not black garlic, on reduction of blood pressure in rats. For instance, following administration of garlic extract at $50 \mathrm{mg} / \mathrm{kg}$ BW by tube feeding for seven days, the systolic blood pressure in rats was significantly reduced $(p<0.05)$ by $29 \mathrm{mmHg}$ compared to the induction group. Similar outcomes were reported by Asdaq and Inamdar [35] and Sharifi et al. [36], showing a reduction of systolic blood pressure in rats by 53.9 and $30 \mathrm{mmHg}$, respectively, following tube feeding of garlic extract at $250 \mathrm{mg} / \mathrm{kg} \mathrm{BW}$ for three weeks for the former and at $50 \mathrm{mg} / \mathrm{kg}$ BW for four weeks for the latter. Apparently, the efficiency of blood pressure reduction in rats can be dependent upon administration dose, feeding period and garlic extract composition. Moreover, the reduction of systolic blood pressure in rats can be due to maintenance of blood vessel elasticity and erythrocyte deformability for improvement in blood circulation. Nevertheless, Harauma and Moriguchi [37] pointed out that a high 
dose of garlic extract may cause side effects such as erythrocyte reduction in stomach and papilloma. In addition, a high dose of garlic extract (500 mg/ $\mathrm{kg} \mathrm{BW)} \mathrm{was} \mathrm{shown} \mathrm{to} \mathrm{be} \mathrm{less}$ effective in reducing blood pressure than that of a medium dose $(250 \mathrm{mg} / \mathrm{kg} \mathrm{BW})$, probably caused by incomplete conversion of allicin to active organosulfur compounds [35]. Thus, compared to raw garlic, black garlic should be less irritating to the stomach as allicin can be degraded during aging [14].

Figure 2A,B show the effect of the administration of black garlic extract and nanoemulsion respectively on kidney weight and volume in DOCA-salt-induced hypertension and its associated mild cognitive impairment in rats. It has been well documented that in DOCA-salt-induced rats, the kidney function can be injured seriously through glomerulosclerosis, tubular fibrosis and tubular dilation [38]. Compared to $\mathrm{C}$ group, the ratio of kidney weight (mg)/body weight $(\mathrm{g})$ in rats for D, PC, HE, HN, LE and LN groups were significantly higher $(p<0.05)$ by $1.58-, 1.40-1.35-, 1.36-, 1.49-$ and $1.40-$ fold, respectively. However, no significant difference $(p>0.05)$ was observed among the PC, HE, HN, LE and LN groups. A similar tendency was shown for the ratio of kidney volume $\left(\mathrm{cm}^{3}\right) /$ body weight $(\mathrm{g})$. By comparison, PC, HE, HN, and LN groups showed a significantly lower $(p<0.05)$ ratio of kidney weight $(\mathrm{mg}) /$ body weight $(\mathrm{g})$ than $\mathrm{D}$ group by $11.1,13.7,12.4$ and $11.5 \%$, respectively. But for the ratio of kidney volume $\left(\mathrm{cm}^{3}\right) /$ body weight $(\mathrm{g}), \mathrm{PC}, \mathrm{HE}$, $\mathrm{HN}$, and LN groups were significantly lower $(p<0.05)$ than $\mathrm{D}$ group by $18.4,17.3,23.9$ and $15.5 \%$, respectively, demonstrating that all the PC, HE, HN, and LN groups could be protective against DOCA-salt-induced kidney impairment in rats. This finding is similar to several previous studies, showing the ratio of kidney weight/body weight in DOCA-saltinduced rats to be higher than C group by 1.76-fold [38], 2.96-fold [39]. and 1.98-fold [40], following administration of hemin, $\alpha$-lipoic acid and L-carnitine, respectively.

The concentration changes of bradykinin, angiotensin II and aldosterone in DOCAsalt-induced hypertension and its associated mild cognitive impairment in rats as affected by black garlic extract and nanoemulsion is shown in Figure 2C-E. Compared to C group, the plasma bradykinin concentration in D group was significantly reduced $(p<0.05)$ by $27.75 \mathrm{pg} / \mathrm{mL}$ (Figure 2C). Of the various groups, only PC, HE and HN could significantly increase $(p<0.05)$ the plasma bradykinin concentration by $25.00,19.86$, and $20.67 \mathrm{pg} / \mathrm{mL}$, respectively, when compared to D group, while both LE and LN groups showed no significant difference $(p>0.05)$.

In Figure 2D, the angiotensin II (Ang II) concentration in plasma of DOCA-saltinduced hypertension rats was significantly higher $(p<0.05)$ than $C$ group by $0.64 \mathrm{ng} / \mathrm{mL}$. However, compared to D group, the Ang II concentration could be significantly reduced $(p<0.05)$ by $0.62,0.59,0.55,0.35$ and $0.42 \mathrm{ng} / \mathrm{mL}$ for PC, HE, HN, LE and LN groups, respectively. Interestingly, there was no significant difference $(p>0.05)$ in Ang II concentration among PC, HE, HN, LE and LN groups.

In Figure 2E, the aldosterone concentration in plasma of DOCA-salt-induced hypertension rats was significantly higher $(p<0.05)$ than $C$ group by $54.25 \mathrm{pg} / \mathrm{mL}$. However, compared to $\mathrm{D}$ group, the aldosterone concentration could be significantly reduced $(p<0.05)$ by $50.80,40.94,47.15,40.43$ and $37.56 \mathrm{pg} / \mathrm{mL}$ for PC, HE, HN, LE and LN groups, respectively, implying that lisinopril was the most effective in reducing aldosterone concentration in rat plasma, followed by high-dose black garlic nanoemulsion. Accordingly, lisinopril, a frequently used anti-hypertension drug, is also an Ang I converting enzyme inhibitor. It has been established that ACE I can combine with ACE to inhibit ACE activity, thereby reducing the formation of Ang II and degradation of bradykinin, and leading to vasodilation and a decrease of blood pressure [41]. Furthermore, the renin-angiotensin-aldosterone system (RAAS) can catalyze the hydrolysis of angiotensinogen from liver into non-active angiotensin I (Ang I), which in turn can be converted to active Ang II through angiotensinconverting enzyme (ACE) for subsequent contraction of vascular smooth muscle and stimulation of adrenal cortex to secrete aldosterone, leading to enhancement of sodium ion absorption by kidney and elevation of blood pressure [42]. In addition, bradykinin can be converted to non-active peptide fragments in the presence of $A C E$, thereby inhibiting 
vasodilation [41]. In several previous studies using the same animal model, the elevation of bradykinin concentration and decrease of aldosterone concentration in rat plasma by a fermented product NTU101 [43], as well as reduction of Ang II concentration in rat plasma by apelin, an active polypeptide [44], were demonstrated.
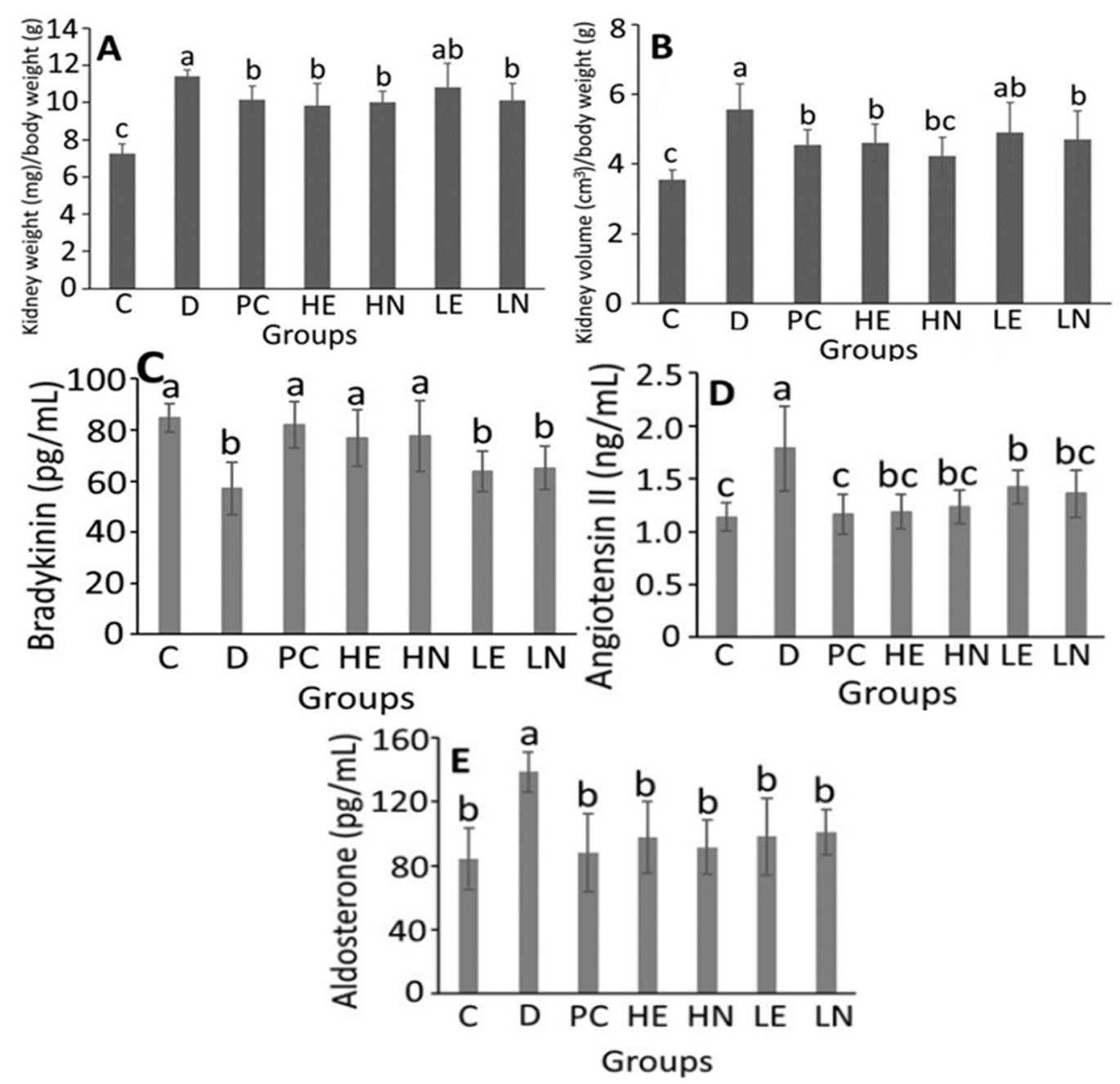

Figure 2. Effect of the administration of black garlic extract and nanoemulsion onkidney weight (A), kidney volume (B), bradykinin (C), angiotensin II (D) and aldosterone (E) in DOCA-salt-induced hypertension and its associated mild cognitive impairment in rats. Data are presented as means \pm standard deviation $(n=6)$; C, control; D, DOCA-salt at a dose $25 \mathrm{mg} / \mathrm{kg}$ BW; PC, DOCA-salt with the administration of lisinopril at a dose $15 \mathrm{mg} / \mathrm{kg}$ BW; HE, DOCA-salt with the administration of black garlic extract at a dose of $100 \mathrm{mg} / \mathrm{kg}$ BW; HN, DOCA-salt with the administration of black garlic nanoemulsion at a dose of $100 \mathrm{mg} / \mathrm{kg} \mathrm{BW}$; LE, DOCA-salt with the administration of black garlic extract at a dose of $50 \mathrm{mg} / \mathrm{kg} \mathrm{BW;} \mathrm{LN,}$ DOCA-salt with the administration of black garlic nanoemulsion at a dose of $50 \mathrm{mg} / \mathrm{kg}$ BW. Values with different small letters $(\mathrm{a}-\mathrm{c})$ are significantly different $(p<0.05)$.

Collectively, both black garlic extract and nanoemulsion prepared in our study could reduce blood pressure in rats through an increase of bradykinin concentration and decrease of both Ang II and aldosterone concentrations in rat plasma with lisinopril, high dose of both black garlic extract and nanoemulsion being the most efficient.

\subsection{Morris Water Maze Test}

Table 3 shows the effect of the administration of black garlic extract and nanoemulsion on reference memory task in Morris water maze test in DOCA-salt-induced hypertension and its associated mild cognitive impairment in rats. Compared to D group, the swimming distance for rats to reach the escape platform could be significantly reduced $(p<0.05)$ by 
273.07, 275.38, 297.29, 250.11 and $253.74 \mathrm{~cm}$ for PC, HE, HN, LE and LN groups, respectively. However, no significant difference $(p>0.05)$ in swimming distance was observed among PC, HE, HN, LE and LN groups. Similarly, compared to D group, the escape latency for PC, HE, HN, LE and LN groups was significantly reduced $(p<0.05)$ by $14.21,14.59,14.82$, 13.06 and $13.20 \mathrm{~s}$, respectively. In addition, no significant difference $(p>0.05)$ in escape latency was shown among PC, HE, HN, LE and LN groups. Likewise, compared to C group, the time length of rats in the target quadrant was significantly reduced $(p<0.05)$ by $16.15 \mathrm{~s}$ for D group (Table S5). However, when compared to D group, all the PC, HE, $\mathrm{HN}, \mathrm{LE}$ and LN groups increased time length of rats in the target quadrant by 15.21, 12.22, 12.46, 5.17 and $7.88 \mathrm{~s}$, respectively (Table S5). Similarly, for average of the other three quadrants, the PC, HE and HN groups could reduce time length of rats by 5.41, 4.18 and $4.27 \mathrm{~s}$, respectively (Table S5 and Figure S1), suggesting that lisinopril and both high-dose black garlic extract and nanoemulsion were more effective in improving long-term memory ability than low-dose black garlic extract and nanoemulsion during the spatial probe test.

Table 3. Effect of the administration of black garlic extract and nanoemulsion on reference and working memory task in Morris water maze in DOCA-salt-induced hypertension and its associated mild cognitive impairment in rats.

\begin{tabular}{|c|c|c|c|c|c|c|}
\hline \multirow{2}{*}{ Group } & \multicolumn{3}{|c|}{ Total Swimming Distance (cm) } & \multicolumn{3}{|c|}{ Escape Latency (s) } \\
\hline & Day 1 & Day 2 & Day 3 & Day 1 & Day 2 & Day 3 \\
\hline \multicolumn{7}{|c|}{ Reference memory task } \\
\hline $\mathrm{C}$ & $767.73 \pm 103.73 \mathrm{Aa}$ & $441.75 \pm 112.66^{\mathrm{Bb}}$ & $224.02 \pm 97.25 \mathrm{Cb}$ & $31.87 \pm 10.15^{\mathrm{Aa}}$ & $18.92 \pm 5.85^{\mathrm{Bb}}$ & $9.92 \pm 4.29 \mathrm{Bb}$ \\
\hline $\mathrm{D}$ & $995.84 \pm 188.73^{\mathrm{Aa}}$ & $713.38 \pm 209.50 \mathrm{ABa}$ & $541.26 \pm 205.86^{\mathrm{Ba}}$ & $50.24 \pm 11.48^{\mathrm{Aa}}$ & $39.19 \pm 8.04 \mathrm{ABa}$ & $28.44 \pm 9.08^{\mathrm{Ba}}$ \\
\hline PC & $842.06 \pm 313.78^{\mathrm{Aa}}$ & $371.96 \pm 173.97 \mathrm{Bb}$ & $281.97 \pm 163.49^{\mathrm{Bb}}$ & $34.33 \pm 13.37$ Аа & $16.67 \pm 7.05^{\mathrm{Bb}}$ & $13.61 \pm 7.11^{\mathrm{Bb}}$ \\
\hline $\mathrm{HE}$ & $791.77 \pm 182.28^{\mathrm{Aa}}$ & $439.65 \pm 182.25^{\mathrm{Bb}}$ & $307.71 \pm 75.56^{\mathrm{Bb}}$ & $37.13 \pm 12.21 \mathrm{Aa}$ & $19.89 \pm 7.01 \mathrm{Bb}$ & $14.57 \pm 5.38^{\mathrm{Bb}}$ \\
\hline $\mathrm{HN}$ & $746.88 \pm 269.54 \mathrm{Aa}$ & $359.68 \pm 129.05^{\mathrm{Bb}}$ & $250.27 \pm 125.73^{\mathrm{Bb}}$ & $36.25 \pm 13.51 \mathrm{Aa}$ & $16.28 \pm 6.31^{\mathrm{Bb}}$ & $12.21 \pm 5.65^{\mathrm{Bb}}$ \\
\hline LE & $907.87 \pm 294.82 \mathrm{Aa}$ & $444.94 \pm 78.91^{\mathrm{Bb}}$ & $301.83 \pm 108.25^{\mathrm{Bb}}$ & $43.02 \pm 12.34 \mathrm{Aa}$ & $21.01 \pm 2.67^{\mathrm{Bb}}$ & $15.44 \pm 4.57^{\mathrm{Bb}}$ \\
\hline \multirow[t]{2}{*}{$\mathrm{LN}$} & $890.78 \pm 343.01^{\mathrm{Aa}}$ & $428.43 \pm 137.43^{\mathrm{Bb}}$ & $375.43 \pm 185.71^{\mathrm{Bab}}$ & $41.31 \pm 20.36^{\mathrm{Aa}}$ & $20.11 \pm 6.31^{\mathrm{Bb}}$ & $18.64 \pm 5.92^{\mathrm{Bb}}$ \\
\hline & Day 5 & Day 6 & Day 7 & Day 5 & Day 6 & Day 7 \\
\hline \multicolumn{7}{|c|}{ Working memory task } \\
\hline $\mathrm{C}$ & $193.56 \pm 114.26^{\mathrm{A}}$ & $156.76 \pm 43.02^{\mathrm{B}}$ & $142.78 \pm 34.08^{\mathrm{B}}$ & $8.93 \pm 6.14^{\mathrm{A}}$ & $6.73 \pm 2.06^{\mathrm{B}}$ & $6.94 \pm 1.93^{\mathrm{B}}$ \\
\hline $\mathrm{D}$ & $783.07 \pm 123.26^{\mathrm{A}}$ & $552.35 \pm 220.46^{\mathrm{B}}$ & $439.66 \pm 101.02^{\mathrm{B}}$ & $35.91 \pm 6.61^{\mathrm{A}}$ & $28.12 \pm 7.57^{\mathrm{A}}$ & $21.52 \pm 3.12^{B}$ \\
\hline PC & $247.31 \pm 137.00^{\mathrm{A}}$ & $231.64 \pm 89.02^{\mathrm{A}}$ & $166.59 \pm 73.52^{\mathrm{B}}$ & $10.49 \pm 7.11^{\mathrm{A}}$ & $8.93 \pm 3.09^{\mathrm{B}}$ & $7.31 \pm 2.53^{B}$ \\
\hline $\mathrm{HE}$ & $306.80 \pm 92.97^{\mathrm{A}}$ & $281.27 \pm 81.48^{\mathrm{A}}$ & $164.28 \pm 91.38^{\mathrm{B}}$ & $14.43 \pm 5.22^{\mathrm{A}}$ & $13.48 \pm 4.54^{\mathrm{A}}$ & $6.93 \pm 3.21^{\mathrm{B}}$ \\
\hline $\mathrm{HN}$ & $323.90 \pm 107.48^{\mathrm{A}}$ & $243.63 \pm 85.15^{B}$ & $142.37 \pm 98.54^{C}$ & $14.87 \pm 6.05^{\mathrm{A}}$ & $11.33 \pm 4.21^{\mathrm{A}}$ & $6.70 \pm 5.61^{\mathrm{B}}$ \\
\hline LE & $426.64 \pm 126.97^{\mathrm{A}}$ & $298.02 \pm 78.58^{\mathrm{B}}$ & $189.55 \pm 66.06^{C}$ & $18.23 \pm 5.67^{\mathrm{A}}$ & $12.92 \pm 1.30^{B}$ & $8.46 \pm 3.01^{C}$ \\
\hline $\mathrm{LN}$ & $447.39 \pm 119.98^{A}$ & $283.72 \pm 94.82^{B C}$ & $185.92 \pm 105.31^{C}$ & $9.43 \pm 6.26^{\mathrm{A}}$ & $7.58 \pm 3.13^{\mathrm{B}}$ & $8.32 \pm 4.12^{\mathrm{B}}$ \\
\hline
\end{tabular}

Data are presented as means \pm standard deviation $(n=6)$; C, control; D, DOCA-salt at a dose $25 \mathrm{mg} / \mathrm{kg}$ BW; PC, DOCA-salt with the administration of lisinopril at a dose $15 \mathrm{mg} / \mathrm{kg}$ BW; HE, DOCA-salt with the administration of black garlic extract at a dose of $100 \mathrm{mg} / \mathrm{kg} \mathrm{BW}$; HN, DOCA-salt with the administration of black garlic nanoemulsion at a dose of $100 \mathrm{mg} / \mathrm{kg}$ BW; LE, DOCA-salt with the administration of black garlic extract at a dose of $50 \mathrm{mg} / \mathrm{kg}$ BW; LN, DOCA-salt with the administration of black garlic nanoemulsion at a dose of $50 \mathrm{mg} / \mathrm{kg}$ BW. Values with different capital letters (A-C) in the same row for total swimming distance or escape latency and small letters $(a, b)$ in the same column for total swimming distance or escape latency are significantly different $(p<0.05)$.

Table 3 also shows the effect of the administration of black garlic extract and nanoemulsion on working memory task in Morris water maze in DOCA-salt-induced hypertension and its associated mild cognitive impairment in rats. On day 5, 6 and 7, D group showed a significantly higher $(p<0.05)$ swimming distance and escape latency than $C$ group. However, compared to D group on day 7, all the PC, HE, HN, LE and LN groups could significantly reduce $(p<0.05)$ swimming distance by $273.07,275.38,297.29,250.11$ and $253.74 \mathrm{~cm}$, respectively, as well as escape latency by $14.21,14.59,14.82,13.06$ and $13.20 \mathrm{~s}$. This outcome further demonstrated that lisinopril and both high-dose black garlic nanoemulsion and extract possessed a more pronounced effect than low-dose black garlic nanoemulsion and extract in improving short memory ability in DOCA-salt-induced hypertension and its associated mild cognitive impairment in rats.

In several previous studies Hermawati et al. [45], reported that a dose (50 mg/ $\mathrm{kg} \mathrm{BW)}$ of black garlic extract could improve space memory ability of monosodium glutamateinduced rats in a Morris maze text. Following intraperitoneal injection of S-allyl cysteine, a major organosulfur compound in black garlic at $30 \mathrm{mg} / \mathrm{kg}$ BW to mice for 15 days, 
the swimming distance and escape latency was reduced by $43 \%$ and $32 \%$, respectively, compared to induction group. This outcome indicated that S-allyl cysteine was effective in preventing cognitive impairment in rats [46]. Likewise, compared to induction group, the administration of garlic extract to rats at $250 \mathrm{mg} / \mathrm{kg}$ BW could reduce escape latency by $47 \%$ and increase time length in the target quadrant by $60 \%$ in a Morris maze test [47], demonstrating again that garlic extract was effective in improving cognitive function. Similar finding was reported by Ghasemi et al. [48] showing a rise of the target quadrant time length by $45 \%$ in a Morris maze test, as well as an increase of latency time to the dark environment by sevenfold in a passive avoidance test following administration of garlic juice at $100 \mathrm{mg} / \mathrm{kg}$ BW to rats.

Taken together, both garlic extract and nanoemulsion were effective in improving learning and memory ability of rats. However, the efficiency may be varied depending on the variety and amount of bioactive compounds in fresh garlic and black garlic. As mentioned before, black garlic contained a higher level of bioactive compounds including diallyl sulfide, diallyl disulfide and diallyl trisulfide, phenolic acids and flavonoids, and thus a more pronounced effect in improving cognitive function ability in rats was observed when compared to many studies dealing with raw garlic extract. However, Farooqui and Farooqui [49] further pointed out that all the bioactive compounds in fresh garlic or black garlic prevent neurodegeneration through the reduction of oxidative pressure and nerve inflammation. Nevertheless, our study further demonstrated that black garlic nanoemulsion was more effective than raw garlic extract in improving cognitive function ability in rats.

3.6. Determination of NO Concentration in Plasma, Oxidative and Inflammation Index in Hippocampus in DOCA-Salt Induced Hypertension and Its Associated Mild Cognitive Impairment in Rats

Table 4 shows the effect of the administration of black garlic extract and nanoemulsion on the nitric oxide (NO) concentration in plasma, contents of TNF- $\alpha$, IL- 6 and IL-1 $\beta$, as well as activities of acetylcholinesterase (AChE), superoxide dismutase (SOD), catalase (CAT), glutathione (GSH), glutathione peroxidase (GSH-Px) and malondialdehyde (MDA) concentrations in hippocampus in DOCA-salt-induced hypertension and its associated mild cognitive impairment in rats. Compared to $\mathrm{C}$ group, the $\mathrm{NO}$ concentration in $\mathrm{D}$ group was reduced by $10.34 \mu \mathrm{M}$. Of the various groups, only PC, HE and $\mathrm{HN}$ could significantly increase $(p<0.05) \mathrm{NO}$ concentration by $10.75,7.21$ and $8.29 \mu \mathrm{M}$, respectively, when compared to D group. It has been well established that in DOCA-salt-induced rats, the hydroperoxide substance can be increased in blood vessel to decrease NO concentration through the reaction with $\mathrm{NO}$ and peroxynitrite formation, leading to endothelial contraction disorder in blood vessels [50,51]. Moreover, following administration of both high-dose black garlic extract and nanoemulsion, the presence of both phenolics and flavonoid compounds could be effective antioxidants in reducing peroxynitrite formation for elevation of $\mathrm{NO}$ concentration and reduction of blood pressure in DOCA-salt-induced rats. 
Table 4. Effect of the administration of black garlic extract and nanoemulsion on nitric oxide concentration in plasma and contents of tumor necrosis factor- $\alpha$ (TNF- $\alpha$ ), interleukin-6 (IL-6) and interleukin-1 $\beta$ (IL-1 $\beta$ ) as well as activities of acetylcholinesterase (AChE), superoxide dismutase (SOD), catalase (CAT), glutathione (GSH), glutathione peroxidase (GSH$\mathrm{Px}$ ) and malondialdehyde (MDA) concentrations in hippocampus in DOCA-salt-induced hypertension and its associated mild cognitive impairment in rats.

\begin{tabular}{|c|c|c|c|c|c|c|}
\hline Groups & \multicolumn{2}{|c|}{ Nitrate + Nitrite $(\mu \mathrm{M})$} & $\begin{array}{l}\text { TNF- } \alpha \\
\text { /g Tissue) }\end{array}$ & \multicolumn{2}{|c|}{$\begin{array}{c}\text { IL-6 } \\
\text { (pg/g Tissue) }\end{array}$} & $\begin{array}{c}\text { IL-1 } \beta \\
\text { (pg/g Tissue) }\end{array}$ \\
\hline $\mathrm{C}$ & \multicolumn{2}{|c|}{$23.28 \pm 5.95^{\mathrm{A}}$} & $53 \pm 79.33^{C}$ & \multicolumn{2}{|c|}{$1890.75 \pm 84.36^{\mathrm{D}}$} & $1465.38 \pm 118.46^{\mathrm{D}}$ \\
\hline $\mathrm{D}$ & \multicolumn{2}{|c|}{$12.94 \pm 3.54^{C}$} & $5 \pm 121.77^{\mathrm{A}}$ & \multicolumn{2}{|c|}{$2684.75 \pm 281.72^{\mathrm{A}}$} & $2833.01 \pm 208.09$ A \\
\hline PC & \multicolumn{2}{|c|}{$23.69 \pm 5.07^{\mathrm{A}}$} & $14 \pm 54.96^{\mathrm{BC}}$ & \multicolumn{2}{|c|}{$1994.86 \pm 215.67 \mathrm{CD}$} & $1599.86 \pm 166.94^{\mathrm{D}}$ \\
\hline $\mathrm{HE}$ & \multicolumn{2}{|c|}{$20.15 \pm 3.81 \mathrm{AB}$} & $38 \pm 94.12^{\text {ВC }}$ & \multicolumn{2}{|c|}{$2227.14 \pm 241.24^{\mathrm{BC}}$} & $1922.57 \pm 130.81^{C}$ \\
\hline $\mathrm{HN}$ & \multicolumn{2}{|c|}{$21.23 \pm 5.08^{\mathrm{AB}}$} & $7 \pm 78.31$ ВС & \multicolumn{2}{|c|}{$2046.83 \pm 123.61^{C D}$} & $2012.33 \pm 267.47^{C}$ \\
\hline $\mathrm{LE}$ & \multicolumn{2}{|c|}{$15.98 \pm 3.87^{\mathrm{BC}}$} & $5 \pm 107.76^{\mathrm{AB}}$ & \multicolumn{2}{|c|}{$2305.17 \pm 194.02^{\text {B }}$} & $2564.34 \pm 208.08^{\text {B }}$ \\
\hline $\mathrm{LN}$ & \multicolumn{2}{|c|}{$15.65 \pm 3.94^{\mathrm{BC}}$} & $63 \pm 97.51^{\mathrm{B}}$ & \multicolumn{2}{|c|}{$2416.67 \pm 175.18^{B}$} & $2360.83 \pm 200.97^{\text {в }}$ \\
\hline Groups & $\begin{array}{c}\text { AChE } \\
\text { (mU/g Tissue) }\end{array}$ & $\begin{array}{c}\text { SOD } \\
\text { (U/g Tissue) }\end{array}$ & $\begin{array}{c}\text { CAT } \\
\text { (mU/g Tissue) }\end{array}$ & $\begin{array}{c}\text { GSH } \\
\text { (nmol/g Tissue) }\end{array}$ & $\begin{array}{c}\text { GSH-Px } \\
\text { (nmol/min/g Tissue) }\end{array}$ & $\begin{array}{c}\text { MDA } \\
\text { (nmol/g Tissue) }\end{array}$ \\
\hline $\mathrm{C}$ & $56.73 \pm 14.27^{\mathrm{B}}$ & $44.80 \pm 3.15^{\mathrm{A}}$ & $514.93 \pm 76.89^{\mathrm{A}}$ & $631.83 \pm 64.16^{\mathrm{A}}$ & $3.91 \pm 1.06^{\mathrm{A}}$ & $113.84 \pm 10.39^{\mathrm{B}}$ \\
\hline $\mathrm{D}$ & $80.78 \pm 16.41^{\mathrm{A}}$ & $33.77 \pm 7.89^{\mathrm{B}}$ & $280.71 \pm 70.29^{\mathrm{D}}$ & $417.23 \pm 69.74^{\mathrm{B}}$ & $1.92 \pm 0.57^{\mathrm{D}}$ & $141.61 \pm 14.77^{\mathrm{A}}$ \\
\hline PC & $51.23 \pm 8.06^{\mathrm{B}}$ & $45.81 \pm 6.02^{\mathrm{A}}$ & $457.38 \pm 114.79 \mathrm{AB}$ & $595.44 \pm 68.85^{\mathrm{A}}$ & $3.58 \pm 0.71^{\mathrm{A}}$ & $116.18 \pm 8.89^{\mathrm{B}}$ \\
\hline $\mathrm{HE}$ & $54.37 \pm 9.97^{\mathrm{B}}$ & $45.00 \pm 5.95^{\mathrm{A}}$ & $369.23 \pm 90.53^{C}$ & $625.28 \pm 96.64^{\mathrm{A}}$ & $3.14 \pm 0.70^{\mathrm{AB}}$ & $121.97 \pm 8.30^{\mathrm{B}}$ \\
\hline $\mathrm{HN}$ & $52.38 \pm 24.09^{B}$ & $43.51 \pm 4.74^{\mathrm{A}}$ & $398.63 \pm 73.87^{C}$ & $651.88 \pm 65.66^{\mathrm{A}}$ & $3.28 \pm 0.67^{\mathrm{AB}}$ & $117.90 \pm 4.88^{B}$ \\
\hline LE & $64.68 \pm 12.40^{B}$ & $37.92 \pm 7.31 \mathrm{AB}$ & $320.65 \pm 61.41 \mathrm{CD}$ & $427.19 \pm 82.71^{\text {B }}$ & $2.25 \pm 0.78^{C}$ & $137.24 \pm 7.00^{\mathrm{A}}$ \\
\hline $\mathrm{LN}$ & $58.87 \pm 11.14^{\text {B }}$ & $40.45 \pm 9.29^{\mathrm{AB}}$ & $353.03 \pm 99.85^{C}$ & $463.07 \pm 47.70^{\mathrm{B}}$ & $2.55 \pm 0.76^{\mathrm{C}}$ & $133.86 \pm 11.45^{\mathrm{A}}$ \\
\hline
\end{tabular}

Data are presented as means \pm standard deviation $(n=6)$; C, control; D, DOCA-salt at a dose $25 \mathrm{mg} / \mathrm{kg} \mathrm{BW}$; PC, DOCA-salt with the administration of lisinopril at a dose $15 \mathrm{mg} / \mathrm{kg} \mathrm{BW}$; HE, DOCA-salt with the administration of black garlic extract at a dose of $100 \mathrm{mg} / \mathrm{kg} \mathrm{BW}$; HN, DOCA-salt with the administration of black garlic nanoemulsion at a dose of $100 \mathrm{mg} / \mathrm{kg}$ BW; LE, DOCA-salt with the administration of black garlic extract at a dose of $50 \mathrm{mg} / \mathrm{kg}$ BW; LN, DOCA-salt with the administration of black garlic nanoemulsion at a dose of $50 \mathrm{mg} / \mathrm{kg}$ BW. Values with different capital letters (A-D) in the same column are significantly different $(p<0.05)$. TNF- $\alpha$, tumor necrosis factor- $\alpha$; IL-6, interleukin-6; IL-1 $\beta$, interleukin-1 $\beta$; AChE, acetylcholinesterase; SOD, superoxide dismutase; CAT, catalase; GSH, glutathione; GSH-Px, glutathione peroxidase; MDA, malondialdehyde.

Acetylcholine, a vital neurotransmitter in brain, can be synthesized and released into synapse for reaction with its receptor for regulation of neurotransmitter release and down-stream message transfer. However, when acetylcholine is present in excess, it can be decomposed into choline and acetyl CoA by AChE for recycle and reuse [52]. Compared to $\mathrm{C}$ group, the AChE activity in hippocampus of rats for $\mathrm{D}$ group was significantly higher $(p<0.05)$ by $24.05 \mathrm{mU} / \mathrm{g}$. However, following administration of PC, HE, HN, LN and LE, the AChE activity in hippocampus of rats was significantly reduced $(p<0.05)$ by 29.55 , $26.41,28.40,21.91$ and $16.10 \mathrm{mU} / \mathrm{g}$, respectively, when compared to D group. Apparently, the presence of $\mathrm{AChE}$ in excess can result in deficiency of acetylcholine for subsequent impairment of memory and cognition [53]. A similar trend was observed for MDA, an index of lipid peroxidation, i.e., the MDA level in hippocampus of rats for D group was significantly higher $(p<0.05)$ than $C$ group by $27.77 \mathrm{nmol} / \mathrm{g}$. However, following administration of PC, HE, HN LN and LE, the MDA level was reduced by 25.43, 19.64, 23.71, 4.37 and $7.75 \mathrm{nmol} / \mathrm{g}$, respectively. For SOD activity in hippocampus of rats, D group was significantly lower $(p<0.05)$ than $C$ group by $11.03 \mathrm{U} / \mathrm{g}$. However, following administration of PC, HE, HN, LN and LE, the SOD activity significantly increased $(p<0.05)$ by 12.04 , $11.23,9.74,4.15$ and $6.68 \mathrm{U} / \mathrm{g}$, respectively, when compared to D group. Similar findings were observed for CAT, GSH and GSH-Px. The CAT activity in hippocampus of rats for D group was significantly lower $(p<0.05)$ than $C$ group by $234.22 \mathrm{mU} / g$. However, following administration of PC, HE, HN, LE and LN, the CAT activity significantly increased $(p<0.05)$ by $176.67,88.52,117.92,39.94$ and $72.32 \mathrm{mU} / \mathrm{g}$, respectively, when compared to D group. For the GSH and GSH-Px activity in hippocampus of rats, D group was significantly lower $(p<0.05)$ than C group by $214.6 \mathrm{nmol} / \mathrm{g}$ and $1.99 \mathrm{nmol} / \mathrm{min} / \mathrm{g}$, respectively. However, compared to D group, a steep rise $(p<0.05)$ of GSH by $178.21,208.05$ and $234.65 \mathrm{nmol} / \mathrm{g}$ as well as GSH-Px by 1.66, 1.22 and $1.36 \mathrm{nmol} / \mathrm{min} / \mathrm{g}$ was respectively shown for PC, HE and $\mathrm{HN}$ groups. Comparatively, all the $\mathrm{PC}, \mathrm{HE}$ and $\mathrm{HN}$ groups were the most effective in enhancing activities of antioxidant enzymes including SOD, CAT, GSH and GSH-Px, 
while minimizing MDA production. Apparently, the enhanced antioxidant activity of black garlic can be associated with phenolic acid, flavonoid and organosulfur compounds, resulting in a higher antioxidant activity than fresh garlic. In a previous study $\mathrm{Li}$ and Kim [54] also reported that following administration of black garlic extract at $50 \mathrm{mg} / \mathrm{kg}$ BW for 4 weeks by tube feeding, both GSH and GSH-Px levels in hippocampus of rats could increase by 50 and $45 \%$, respectively, while both AChE and MDA levels reduced by 32 and $24 \%$. In addition, Kumar [55] demonstrated that the inhibition of $\mathrm{AChE}$ and butyryl cholinesterase (BChE) activities can be attributed to the presence of major bioactive compounds in garlic such as allicin. Nevertheless, both phenolic acids and flavonoids in black garlic nanoemulsion should also play a vital role in inhibiting $\mathrm{AChE}$ and $\mathrm{BChE}$ activities. Likewise, following tube feeding of garlic extract to rats at $250 \mathrm{mg} / \mathrm{kg}$ BW for 9 weeks, the activities of SOD, GSH-Px and CAT rose by $102 \%, 117 \%$ and $34 \%$, respectively, while the MDA level reduced by $58 \%$. Obviously, the difference in antioxidant activity of fresh garlic or black garlic can also be caused by difference in animal model, dose, sample variety, feeding period and method of determining oxidative index. Collectively, the drug lisinopril as well as both high-dose black garlic extract and nanoemulsion were the most effective in enhancing SOD, CAT, GSH and GSH-Px activities while minimizing both AChE and MDA levels.

For the inflammation index, compared to C group, the levels of TNF- $\alpha$, IL- 6 and IL-1 $\beta$ were significantly higher $(p<0.05)$ by $283.22,794.00$ and $1367.63 \mathrm{pg} / \mathrm{g}$ for $\mathrm{D}$ group, respectively. However, following administration of PC, HE, HN, LE and LN, the TNF- $\alpha$ level was reduced by 216.31, 191.87, 203.18, 103.40 and $116.12 \mathrm{pg} / \mathrm{g}$, respectively, when compared to D group. Likewise, compared to D group, the levels of IL-6 were reduced by $689.89,457.61,637.92,379.58$ and $268.08 \mathrm{pg} / \mathrm{g}$ for PC, HE, HN, LE and LN groups, respectively, as well as $1233.15,910.44,820.68,268.67$ and $472.18 \mathrm{pg} / \mathrm{g}$ for PC, HE, HN, LE and LN groups for the IL- $1 \beta$ level. By comparison, the PC, HE and HN groups were the most effective in reducing TNF- $\alpha$, IL- 6 and IL- $1 \beta$ levels. Likewise, following administration of fresh garlic or black garlic extracts by tube feeding at $120 \mathrm{mg} / \mathrm{kg}$ BW, the TNF- $\alpha$ level in serum was reduced by 56 and $52 \%$, respectively, as well as IL- 6 level by $10 \%$ and $15 \%$, when compared to the induction group [10]. In addition, after tube feeding of raw garlic extract at $250 \mathrm{mg} / \mathrm{kg} \mathrm{BW}$, the IL-1 $\beta$ level was reduced by $50 \%$. All these studies suggested that both fresh garlic and black garlic extracts possessed anti-inflammatory effect. Nevertheless, raw garlic extract was shown to possess a higher cell toxicity towards macrophage RAW 264.7 than black garlic extract [10]. Thus, from the safety point of view, black garlic should be more important than fresh garlic for future biomedical applications.

\section{Conclusions}

In conclusion, both black garlic extracts and nanoemulsions can improve DOCA-saltinduced hypertension in rats through an increase of bradykinin concentration and decrease of aldosterone and Ang II concentrations as well as increase of NO production, while the learning and memory ability of rats can be improved through reduction of AChE activity, oxidative stress and inflammation as well as enhancement of antioxidant enzyme activity (Figure S2). Further research is necessary to explore the possibility of future clinical trial for treatment of patients with dementia disease.

Supplementary Materials: The following are available online at https:/ / www.mdpi.com/article/10 $.3390 /$ antiox10101611/s1.

Author Contributions: Conceptualization, B.-H.C.; methodology, C.-Y.C. and T.-Y.T.; software, C.Y.C. and T.-Y.T.; validation, C.-Y.C. and T.-Y.T.; formal analysis, C.-Y.C. and T.-Y.T.; investigation, C.-Y.C. and T.-Y.T.; resources, B.-H.C.; data curation, C.-Y.C. and T.-Y.T.; writing-original draft preparation, B.-H.C.; writing-review and editing, B.-H.C.; visualization, C.-Y.C. and T.-Y.T.; supervision, B.-H.C.; project administration, B.-H.C.; funding acquisition, B.-H.C. All authors have read and agreed to the published version of the manuscript. 
Funding: This research was funded by Ministry of Science and Technology Taiwan, grant number 106-2622-B-030-001-CC2.

Institutional Review Board Statement: The study was conducted according to the guidelines of the Declaration of Helsinki, and approved by the Ethical Committee of Animal Subjects Review Committee of Fu Jen Catholic University (protocol code: A10602 and date of approval: 1 June 2017).

Informed Consent Statement: Not applicable.

Data Availability Statement: Data is contained within the article or Supplementary Material.

Acknowledgments: The authors wish to thank Yen-Sheng Wu from Tzong Jao Hang's Electron Microscope Laboratory, School of Medicine, Fu Jen Catholic University, New Taipei City, Taiwan for technical assistance in recording TEM images.

Conflicts of Interest: The authors declare no conflict of interest.

\section{References}

1. Al-Qattan, K.; Thomson, M.; Ali, M. Garlic (Allium sativum) and ginger (Zingiber officinale) attenuate structural nephropathy progression in streptozotocin-induced diabetic rats. Eur. e-J. Clin. Nutr. Metab. 2008, 3, e62-e71. [CrossRef]

2. Queiroz, Y.S.; Ishimoto, E.Y.; Bastos, D.H.M.; Sampaio, G.R.; Torres, E.A.F.S. Garlic (Allium sativum L.) and ready-to-eat garlic products: In vitro antioxidant activity. Food Chem. 2009, 115, 371-374. [CrossRef]

3. Choi, I.S.; Cha, H.S.; Lee, Y.S. Physicochemical and antioxidant properties of black garlic. Molecules 2014, 19, 16811-16823. [CrossRef] [PubMed]

4. Sato, E.; Kohno, M.; Hamano, H.; Niwano, Y. Increased anti-oxidative potency of garlic by spontaneous short-term fermentation. Plant Foods Hum. Nutr. 2006, 61, 157-160. [CrossRef] [PubMed]

5. Kim, J.H.; Nam, S.H.; Rico, C.W.; Kang, M.Y. A comparative study on the antioxidative and anti-allergic activities of fresh and aged black garlic extracts. Int. J. Food Sci. Technol. 2012, 47, 1176-1182. [CrossRef]

6. Martínez-Casas, L.; Lage-Yusty, M.; López-Hernández, J. Changes in the aromatic profile, sugars, and bioactive compounds when purple garlic is transformed into black garlic. J. Agric. Food Chem. 2017, 65, 10804-10811. [CrossRef]

7. Xu, G.; Ye, X.; Chen, J.; Liu, D. Effect of heat treatment on the phenolic compounds and antioxidant capacity of citrus peel extract. J. Agric. Food Chem. 2007, 55, 330-335. [CrossRef] [PubMed]

8. Kim, J.-S.; Kang, O.-J.; Gweon, O.-C. Changes in the content of fat- and water-soluble vitamins in black garlic at the different thermal processing steps. Food Sci. Biotechnol. 2013, 22, 283-287. [CrossRef]

9. Tsai, J.-C.; Chen, Y.-A.; Wu, J.-T.; Cheng, K.-C.; Lai, P.-S.; Liu, K.-F.; Lin, Y.-K.; Huang, Y.-T.; Hsieh, C.-W. Extracts from fermented black garlic exhibit a hepatoprotective effect on acute hepatic injury. Molecules 2019, 24, 1112. [CrossRef]

10. Kim, M.J.; Yoo, Y.C.; Kim, H.J.; Shin, S.K.; Sohn, E.J.; Min, A.Y.; Sung, N.Y.; Kim, M.R. Aged black garlic exerts anti-inflammatory effects by decreasing no and proinflammatory cytokine production with less cytoxicity in LPS-stimulated raw 264.7 macrophages and LPS-induced septicemia mice. J. Med. Food 2014, 17, 1057-1063. [CrossRef]

11. Dong, M.; Yang, G.; Liu, H.; Liu, X.; Lin, S.; Sun, D.; Wang, Y. Aged black garlic extract inhibits HT29 colon cancer cell growth via the PI3K/Akt signaling pathway. Biomed. Rep. 2014, 2, 250-254. [CrossRef] [PubMed]

12. ADI. Alzheimer's Disease International. Available online: https:/ /www.alzint.org/ (accessed on 4 April 2021).

13. Walker, K.A.; Power, M.C.; Gottesman, R.F. Defining the Relationship Between Hypertension, Cognitive Decline, and Dementia: A Review. Curr. Hypertens. Rep. 2017, 19, 24. [CrossRef]

14. Zhang, X.; Li, N.; Lu, X.; Liu, P.; Qiao, X. Effects of temperature on the quality of black garlic. J. Sci. Food Agric. 2016, 96, 2366-2372. [CrossRef] [PubMed]

15. Chiu, C.-W.; Kao, T.-H.; Chen, B.-H. Improved analytical method for determination of cholesterol-oxidation products in meat and animal fat by QuEChERS coupled with gas chromatography-mass spectrometry. J. Agric. Food Chem. 2018, 66, 3561-3571. [CrossRef] [PubMed]

16. Tocmo, R.; Wang, C.; Liang, D.; Huang, D. Organosulphide profile and hydrogen sulphide-releasing capacity of garlic (Allium sativum L.) scape oil: Effects of $\mathrm{pH}$ and cooking. J. Funct. Foods 2015, 17, 410-421. [CrossRef]

17. Kao, T.H.; Huang, C.W.; Chen, B.H. Functional components in Luffa cylindrica and their effects on anti-inflammation of macrophage cells. Food Chem. 2012, 135, 386-395. [CrossRef] [PubMed]

18. American Psychological Association. Guidelines for Ethical Conduct in the Care and Use of Nonhuman Animals in Research; American Psychological Association: Washington, DC, USA, 2012.

19. Morris, R. Developments of a water-maze procedure for studying spatial learning in the rat. J. Neurosci. Methods 1984, 11, 47-60. [CrossRef]

20. Sun, Z.K.; Ma, X.R.; Jia, Y.J.; Liu, Y.R.; Zhang, J.W.; Zhang, B.A. Effects of resveratrol on apoptosis in a rat model of vascular dementia. Exp. Ther. Med. 2014, 7, 843-848. [CrossRef]

21. Hodges, D.M.; DeLong, J.M.; Forney, C.F.; Prange, R.K. Improving the thiobarbituric acid-reactive-substances assay for estimating lipid peroxidation in plant tissues containing anthocyanin and other interfering compounds. Planta 1999, 207, 604-611. [CrossRef] 
22. Statistical Analysis System. SAS Procedures and SAS/Graph User's Guide, Version 6; Statistical Analysis System Institute: Cary, NC, USA, 2014.

23. Taiwan Food and Drug Administration. Method Validation of Food Analysis; Taiwan Food and Drug Administration: Taipei, Taiwan, 2013. (In Chinese)

24. Locatelli, D.A.; Altamirano, J.C.; González, R.E.; Camargo, A.B. Home-cooked garlic remains a healthy food. J. Funct. Foods 2015, 16, 1-8. [CrossRef]

25. Tocmo, R.; Wu, Y.; Liang, D.; Fogliano, V.; Huang, D. Boiling enriches the linear polysulfides and the hydrogen sulfide-releasing activity of garlic. Food Chem. 2017, 221, 1867-1873. [CrossRef]

26. Zhang, Z.; Lei, M.; Liu, R.; Gao, Y.; Xu, M.; Zhang, M. Evaluation of alliin, saccharide contents and antioxidant activities of black garlic during thermal processing. J. Food Biochem. 2015, 39, 39-47. [CrossRef]

27. Purev, U.; Chung, M.J.; Oh, D.-H. Individual differences on immunostimulatory activity of raw and black garlic extract in human primary immune cells. Immunopharmacol. Immunotoxicol. 2012, 34, 651-660. [CrossRef]

28. Thach, N.A.; Thuy, N.M. Effect of extraction conditions on polyphenols, flavonoids, s-allyl cysteine content and antioxidant activity of black garlic extracts. Vietnam J. Sci. Technol. 2017, 55, 18. [CrossRef]

29. Lakshmi, P.; Kumar, G.A. Nanosuspension technology: A review. Int. J. Pharm. Sci. 2010, 2, 35-40.

30. Mahdi, E.S.; Noor, A.M.; Sakeena, M.H.; Abdullah, G.Z.; Abdulkarim, M.F.; Sattar, M.A. Formulation and in vitro release evaluation of newly synthesized palm kernel oil esters-based nanoemulsion delivery system for $30 \%$ ethanolic dried extract derived from local Phyllanthus urinaria for skin antiaging. Int. J. Nanomed. 2011, 6, 2499. [CrossRef]

31. Baccarin, T.; Lemos-Senna, E. Potential application of nanoemulsions for skin delivery of pomegranate peel polyphenols. AAPS PharmSciTech 2017, 18, 3307-3314. [CrossRef]

32. Bazana, M.T.; da Silva, S.S.; Codevilla, C.F.; de Deus, C.; Lucas, B.N.; Ugalde, G.A.; Mazutti, M.A.; Moraes Flores, E.M.; Barin, J.S.; de Bona da Silva, C.; et al. Development of nanoemulsions containing Physalis peruviana calyx extract: A study on stability and antioxidant capacity. Food Res. Int. 2019, 125, 108645. [CrossRef] [PubMed]

33. Vallon, V.; Huang, D.Y.; Grahammer, F.; Wyatt, A.W.; Osswald, H.; Wulff, P.; Kuhl, D.; Lang, F. SGK1 as a determinant of kidney function and salt intake in response to mineralocorticoid excess. Am. J. Physiol. Regul. Integr. Comp. Physiol. 2005, 289, R395-R401. [CrossRef] [PubMed]

34. Thunhorst, R.L.; Beltz, T.G.; Johnson, A.K. Glucocorticoids increase salt appetite by promoting water and sodium excretion. Am. J. Physiol. Regul. Integr. Comp. Physiol. 2007, 293, R1444-R1451. [CrossRef] [PubMed]

35. Asdaq, S.M.B.; Inamdar, M.N. The potential benefits of a garlic and hydrochlorothiazide combination as antihypertensive and cardioprotective in rats. J. Nat. Med. 2011, 65, 81-88. [CrossRef]

36. Sharifi, A.M.; Darabi, R.; Akbarloo, N. Investigation of antihypertensive mechanism of garlic in $2 \mathrm{~K} 1 \mathrm{C}$ hypertensive rat. J. Ethnopharmacol. 2003, 86, 219-224. [CrossRef]

37. Harauma, A.; Moriguchi, T. Aged garlic extract improves blood pressure in spontaneously hypertensive rats more safely than raw garlic. J. Nutr. 2006, 136, 769S-773S. [CrossRef]

38. Jadhav, A.; Torlakovic, E.; Ndisang, J.F. Hemin therapy attenuates kidney injury in deoxycorticosterone acetate-salt hypertensive rats. Am. J. Physiol. Ren. Physiol. 2009, 296, F521-F534. [CrossRef] [PubMed]

39. Takaoka, M.; Kobayashi, Y.; Yuba, M.; Ohkita, M.; Matsumura, Y. Effects of $\alpha$-lipoic acid on deoxycorticosterone acetate-saltinduced hypertension in rats. Eur. J. Pharmacol. 2001, 424, 121-129. [CrossRef]

40. O'Brien, D.; Chunduri, P.; Iyer, A.; Brown, L. 1-Carnitine attenuates cardiac remodelling rather than vascular remodelling in deoxycorticosterone acetate-salt hypertensive rats. Basic Clin. Pharmacol. Toxicol. 2010, 106, 296-301. [CrossRef]

41. Zaman, M.A.; Oparil, S.; Calhoun, D.A. Drugs targeting the renin-angiotensin-aldosterone system. Nat. Rev. Drug Discov. 2002, 1, 621-636. [CrossRef]

42. Carey, R.M.; Siragy, H.M. Newly recognized components of the renin-angiotensin system: Potential roles in cardiovascular and renal regulation. Endocr. Rev. 2003, 24, 261-271. [CrossRef] [PubMed]

43. Cheng, M.-C.; Pan, T.-M. Prevention of hypertension-induced vascular dementia by Lactobacillus paracasei subsp. paracasei NTU 101-fermented products. Pharm. Biol. 2017, 55, 487-496. [CrossRef] [PubMed]

44. Akcılar, R.; Turgut, S.; Caner, V.; Akcllar, A.; Ayada, C.; Elmas, L.; Özcan, T.O. Apelin effects on blood pressure and RAS in DOCA-salt-induced hypertensive rats. Clin. Exp. Hypertens. 2013, 35, 550-557. [CrossRef] [PubMed]

45. Hermawati, E.; Sari, D.C.R.; Partadiredja, G. The effects of black garlic ethanol extract on the spatial memory and estimated total number of pyramidal cells of the hippocampus of monosodium glutamate-exposed adolescent male Wistar rats. Anat. Sci. Int. 2015, 90, 275-286. [CrossRef]

46. Javed, H.; Khan, M.M.; Khan, A.; Vaibhav, K.; Ahmad, A.; Khuwaja, G.; Ahmed, M.E.; Raza, S.S.; Ashafaq, M.; Tabassum, R.; et al. S-allyl cysteine attenuates oxidative stress associated cognitive impairment and neurodegeneration in mouse model of streptozotocin-induced experimental dementia of Alzheimer's type. Brain Res. 2011, 1389, 133-142. [CrossRef]

47. Hiranya, P.; Jirapas, S.; Luerat, S.; Nattayaporn, A.; Nipon, C.; Siriporn, C. Garlic extract attenuates brain mitochondrial dysfunction and cognitive deficit in obese-insulin resistant rats. Appl. Physiol. Nutr. Metab. 2014, 39, 1373-1379. [CrossRef] 
48. Ghasemi, S.; Hosseini, M.; Feizpour, A.; Alipour, F.; Sadeghi, A.; Vafaee, F.; Mohammadpour, T.; Soukhtanloo, M.; Ebrahimzadeh Bideskan, A.; Beheshti, F. Beneficial effects of garlic on learning and memory deficits and brain tissue damages induced by lead exposure during juvenile rat growth is comparable to the effect of ascorbic acid. Drug Chem. Toxicol. 2017, 40, 206-214. [CrossRef] [PubMed]

49. Farooqui, T.; Farooqui, A.A. Neuroprotective Effects of garlic in model systems of neurodegenerative diseases. In Role of the Mediterranean Diet in the Brain and Neurodegenerative Diseases; Farooqui, T., Farooqui, A.A., Eds.; Academic Press: Cambridge, MA, USA, 2018; Chapter 16; pp. 253-269.

50. Ghosh, M.; Wang, H.D.; McNeill, J.R. Role of oxidative stress and nitric oxide in regulation of spontaneous tone in aorta of DOCA-salt hypertensive rats. Br. J. Pharmacol. 2004, 141, 562-573. [CrossRef]

51. Schulz, E.; Jansen, T.; Wenzel, P.; Daiber, A.; Münzel, T. Nitric oxide, tetrahydrobiopterin, oxidative stress, and endothelial dysfunction in hypertension. Antioxid. Redox Signal. 2008, 10, 1115-1126. [CrossRef]

52. Soreq, H.; Seidman, S. Acetylcholinesterase-New roles for an old actor. Nat. Rev. Neurosci. 2001, 2, 294-302. [CrossRef]

53. Tian, Q.; Lin, Z.Q.; Wang, X.C.; Chen, J.; Wang, Q.; Gong, C.X.; Wang, J.Z. Injection of okadaic acid into the meynert nucleus basalis of rat brain induces decreased acetylcholine level and spatial memory deficit. Neuroscience 2004, 126, 277-284. [CrossRef] [PubMed]

54. Li, F.; Kim, M.R. Effect of aged garlic ethyl acetate extract on oxidative stress and cholinergic function of scopolamine-Induced cognitive impairment in mice. Prev. Nutr. Food Sci. 2019, 24, 165-170. [CrossRef] [PubMed]

55. Kumar, S. Dual inhibition of acetylcholinesterase and butyrylcholineesterase enzymes by allicin. Indian J. Pharmacol. 2015, 47, 444-446. [CrossRef] [PubMed] 